\title{
GENE EXPRESSION IN HUMAN ADIPOSE-DERIVED STEM CELLS: COMPARISON OF 2D FILMS, 3D ELECTROSPUN MESHES OR CO- CULTURED SCAFFOLDS WITH TWO-WAY PARACRINE EFFECTS
}

\author{
S.C. Hess' ${ }^{1}$, W.J. Stark ${ }^{1}$, D. Mohn ${ }^{1,2}$, N. Cohrs ${ }^{1}$, S. Märsmannn ${ }^{3,4}$, M. Calcagni ${ }^{3}$, P. Cinelli4, ${ }^{4,}$ \\ and J. Buschmann ${ }^{3,3, *}$
}

${ }^{1}$ Institute for Chemical and Bioengineering, Department of Chemistry and Applied Biosciences, ETH Zurich, CH-8093 Zurich, Switzerland

${ }^{2}$ Clinic for Preventive Dentistry, Periodontology and Cariology, University of Zurich, Centre for Dental Medicine, Plattenstr. 11, CH-8032 Zurich, Switzerland

${ }^{3}$ Division of Plastic and Hand Surgery, University Hospital Zurich, Rämistrasse 100, CH-8091 Zurich, Switzerland

${ }^{4}$ Division of Trauma Surgery, University Hospital Zurich, Rämistrasse 100, CH-8091 Zurich, Switzerland

$\S$ These authors contributed equally to this work as senior authors.

\begin{abstract}
Finding the appropriate cues to trigger the desired differentiation is a challenge in tissue engineering when stem cells are involved. In this regard, three-dimensional environments are often compared to cells' twodimensional culture behaviour (plastic culture dish). Here, we compared the gene expression pattern of human adipose-derived stem cells (ASC) seeded in a three-dimensional (3D) electrospun mesh and on a two-dimensional (2D) film - both of exactly the same material. Additionally, we conducted experiments with a scaffold floating above a film to investigate two-way paracrine effects (co-system). Electrospun meshes (3D scaffolds) and films (2D), consisting either of pristine poly-lactic-co-glycolic acid (PLGA) or of PLGA-containing dispersed amorphous calcium phosphate nanoparticles (PLGA/aCaP), were seeded with ASCs and cultured either in Dulbecco Minimum Essential Medium (DMEM) or in osteogenic medium. After two weeks, minimum stem cell criteria markers as well as typical markers for osteogenesis, endothelial cell differentiation, adipogenesis and chondrogenesis were analysed by quantitative real-time PCR. Interestingly, mostly osteogenic genes of cells seeded on 3D meshes were upregulated compared to those on 2D films, while stem cell markers seemed to be only slightly affected. Runx2 and osteocalcin showed an especially strong upregulation under all conditions, while most other factors analysed for 2D/3D changes were highly dependent on the material composition, the culture medium and on paracrine signalling effects. The beneficial 3D environment for stem cells found in many studies has therefore not to be attributed to the third dimension alone and should carefully be compared to 2D films fabricated of the same material. Furthermore, paracrine interactions triggering differentiation are not negligible.
\end{abstract}

Key words: PLGA, amorphous calcium phosphate, apatite, nanoparticle, adipose-derived stem cell, composite, PCR, stem cells, differentiation.

*Address for correspondence: Dr. Johanna Buschmann, University Hospital Zurich, Plastic Surgery and Hand Surgery, E LAB 27, Sternwartstrasse 14, CH-8091 Zürich, Switzerland.

E-mail: johanna.buschmann@usz.ch

\section{Introduction}

Tissue engineering of artificial organs intended at refilling and closing defects after resections, involves cell seeding on scaffold materials. When using stem cells for fabrication of an implant, a central question is how to trigger their differentiation towards a specific cell type. Adding supplements to the culture media (Zuk et al., 2001) or co-culturing with a different cell type (Lin et al., 2016) are well known options to support differentiation towards various cell fates. Establishment of spheroids (Emmert et al., 2013; Kapur et al., 2012) or cell seeding on posts using two-dimensional (2D) micro-engineering ( $\mathrm{Li}$ and Kilian, 2015) may also act as appropriate strategies. Furthermore, applying dynamic conditions such as perfusion (Heo et al., 2016), mechanical (Xu et al., 2015) or magnetic stimulation (Lima et al., 2015) may improve differentiation toward the desired cell type. Finally, material characteristics such as 
composition (Lee et al., 2016), surface properties, architectural features (Li and Kilian, 2015), pore size and pore connectivity (Viswanathan et al., 2015) are cues for stem cell differentiation into a certain cell type. Substrate stiffness may not only affect adherence and morphology, as shown for fibroblasts seeded on polyacrylamide hydrogels with gradients in mechanical properties (Diederich et al., 2013). However, it may be essential in terms of genomic integrity and differentiation of stem cells, as reported for murine embryonic stem cells seeded on gelatincoated feeder layers of different stiffness (Sthanam et al., 2017).

During stem cell expansion in vitro, the advantages of seeding cells in a three-dimensional (3D) environment over 2D culture conditions have been widely investigated. However, the materials in the 3D environment are often different from the materials of the 2D setting (Neofytou et al., 2011) and, therefore, do not allow attributing the observed advantages to the third dimension alone. For example, a study reports the comparison of $2 \mathrm{D}$ to $3 \mathrm{D}$ culture where human bone-marrow derived stem cells are seeded onto a 3D collagen sponge (commercially available Spongostan ${ }^{\circledR}$ ). The cells' differentiation towards osteoblasts is compared to 2D conditions in noncoated culture dishes (Castren et al., 2015). Although the "real" 2D-3D comparison by using identical materials has also been reported, this comparison refers to adhesion and proliferation of human mesenchymal progenitor cells. However, when gene expression is analysed, again, it is compared to that of cells cultured in a 2D polystyrene dish (Viswanathan et al., 2015).

Obviously, there is a gap in the current literature: The impact of stem cell seeding in a 3D environment (often claimed to be superior to 2D) should be compared to a $2 \mathrm{D}$ environment of the same material. In other words, there is a high demand for an accurate and reliable control group in order to determine the effect of the third dimension. Not much attention has been paid to this aspect so far.

Hence, in the study presented here, we address the following questions: (i) how does gene expression of human adipose-derived stem cells (ASCs) change from a 2D environment (casted film) to a 3D environment (electrospun fibre mesh) made of the same material? (ii) are there any two-way paracrine signalling effects (cell cross talk) when 2D films and 3D meshes are cultivated in the same system, as compared to each type cultured individually (cosystem)? (iii) is there any effect upon gene expression between cells cultured 2D or 3D when scaffolds are cultured simultaneously in this co-system?

\section{Materials and Methods}

\section{Cell isolation}

Human ASCs were isolated from fat tissue with the consent of the patient according to Swiss (KEK-ZH:
StV 7-2009) and international ethical guidelines (ClinicalTrials.gov Identifier: NCT01218945) as reported in (Buschmann et al., 2013). The extraction procedure was performed according to Zuk et al. (2001). ASCs were characterised according to established procedures (Buschmann et al., 2012; Gronthos et al., 2001). Of the 30 isolated primary ASCs (Buschmann et al., 2013), one was selected based on findings in a previous study concerning its differentiation capacity; where it is shown to differentiate easily towards the endothelial cell (EC) phenotype and, moderately to well, towards osteoblasts (OBs) (Gao et al., 2014). The fat for these primary cells had been received from a 29-year old woman by abdominal liposuction. Passages 7-9 were used for all experiments.

\section{Multilineage cell differentiation}

Lineage specific differentiation of ASCs towards the $\mathrm{OB}$, the adipogenic, the chondrogenic cell lineage and the EC differentiation were achieved using StemPro Osteogenesis Differentation Kit (Cat. No. A1007201, Fa. Gibco), StemPro Adipogenesis Differentation Kit (Cat.No. A1007001, Fa. Gibco) and StemPro Chondrogenesis Differentation Kit (Cat. No. A1007101, Fa. Gibco), respectively and for EC differentiation cell culture media supplementation according to Zuk et al. (2001). Von Kossa and Alizarin red staining were used to semi-quantitatively evaluate osteogenic differentiation extent (Fig. 6 and 7), CD31 immunohistochemical staining to assess the endothelial cell differentiation (Fig. 7), Alcian Blue staining in order to evaluate the ability of the ASCs to differentiate towards chondrocytes (Fig. 7) and Oil Red $\mathrm{O}$ staining to verify adipogenic differentiation (Fig. 7).

\section{Scaffold materials}

Clinically approved PLGA (85:15) was received from Boehringer Ingelheim. The aCaP nanoparticles $(\mathrm{Ca} / \mathrm{P}=1.5)$ were prepared by flame spray pyrolysis as described by Loher et al.( 2005), using calcium2-ethylhexanoic salt (synthesised with calcium hydroxide from Riedel de Haen, Ph. Eur. and ethylhexanoic acid from Sigma-Aldrich) and tributyl phosphate (Sigma-Aldrich, $98 \%$ ). PLGA/ aCaP nanocomposites were prepared according to Schneider et al. (2008). To combine the two components, the aCaP nanoparticles were dispersed in chloroform (Riedel de Haen, Ph. Eur.) containing $5 \mathrm{wt} \%$ (referring to the later on added polymer) Tween20 (Polysorbate20, Fluka, Ph. Eur.) using an ultrasonic bath (Bandelin Sonorex Digitec). PLGA (8 $\mathrm{wt} \%$ in chloroform) was added to the dispersion (PLGA/aCaP $=60 / 40 \mathrm{wt}$ ) and the mixture was stirred at room temperature overnight. Pure PLGA solutions (prepared without corresponding amount of nanoparticles) and the PLGA/aCaP dispersions were electrospun (Device: IME EC-CLI, relative humidity: $50 \%$, feeding rate: $2 \mathrm{~mL} / \mathrm{h}$; distance tipcollector: $15 \mathrm{~cm}$; voltage applied: $22 \mathrm{kV}$; tip kept in 
a chloroform airstream) (Schneider et al., 2008). The surface of the as-prepared scaffolds was investigated by means of scanning electron microscopy (SEM, FEI, Nova NanoSEM 450) (Fig. 1).

Disks with a diameter of $1 \mathrm{~cm}$ and a wall thickness of 500-600 $\mu \mathrm{m}$ were prepared with electrospun PLGA and PLGA/aCaP (Buschmann et al., 2012). Moreover, disks with a diameter of $3 \mathrm{~cm}$ were prepared from solvent casted films for 2D cell culture studies.

\section{Tensile properties}

Tensile properties of the materials were measured using dumbbells. Briefly, five dumbbells of each material were punched with a geometry as given in Fig. 9. The thickness of each specimen was determined according to equation 1 ., where $t$ denotes the thickness, $m$ the mass of each individual specimen and $\mathrm{Q}$ the bulk density of the materials. The density of the pure PLGA was $\varrho_{\text {PLGA }}=1.30 \mathrm{~g} \mathrm{~cm}^{3}$ and the density of the particle-loaded composite was $Q_{\text {PLGA }}$ ${ }_{\mathrm{aCaP}}=2.04 \mathrm{~g} \mathrm{~cm}^{3}$. A is the surface of the dumbbell and has a value of $3.3 \mathrm{~cm}^{3}$. The mechanical properties were tested using a tensile tester (Shimadzu AGS-X, 100 N load cell, Reinach Switzerland). The gauge length was $15 \mathrm{~mm}$, and the test speed was $2 \mathrm{~mm} \mathrm{~min}^{1}$ for 3D samples and $100 \mathrm{~mm}$ min $^{1}$ for 2D samples. Engineering stress and engineering strain were measured and a tangent in the linear regime of the stress-strain curve was used to determine the elastic modulus. Measurements were made until failure of the material.

$$
t=\frac{m}{\rho A}
$$

\section{Tissue engineered constructs}

The PLGA and PLGA/aCaP disks, respectively, were soaked in $5 \mathrm{~mL}$ DMEM medium (P04-03550, PAN Biotech, Switzerland) with $10 \%$ of FBS and $50 \mu \mathrm{g} \mathrm{mL}^{-1}$ gentamycin for $15 \mathrm{~min}$ and dried in the laminar flow bench. For cell seeding $1.0 \times 10^{6}$ ASCs were placed on both sides of the disk $(n=3)$. The cells were distributed homogenously over the disk surfaces. All seeded scaffolds were cultivated in 6-well plates using $2 \mathrm{~mL}$ DMEM medium with $10 \%$ of FBS and $50 \mu \mathrm{g} \mathrm{mL}^{-1}$ gentamycin or osteogenic medium (DMEM with $10 \%$ FBS, $50 \mu \mathrm{g} \mathrm{mL} \mathrm{m}^{-1}$ gentamycin, $10 \mathrm{mM}$ beta-glycerophosphate, $50 \mu \mathrm{M}$ ascorbic-2phosphate and $100 \mathrm{nM}$ dexamethasone) for 2 weeks in a humidified atmosphere of $95 \%$ air and $5 \% \mathrm{CO}_{2}$ at $37{ }^{\circ} \mathrm{C}$. Medium was changed every 3 or $4 \mathrm{~d}$. At the end of the experiment ( 2 weeks), the samples were carefully collected and $1 / 4$ were fixed overnight in $4 \%$ formalin in phosphate buffered saline (Kantonsapotheke Zurich, Switzerland), followed by histology and the rest for real time polymerase-chain reaction (PCR). As for the film experiments, the films were seeded with $1.0 \times 10^{6}$ ASCs and they were laid on the bottom of a 6-well plate, either alone or beneath the cell-seeded corresponding 3D mesh, floating in the culture medium with or without osteogenic supplements $(n=3)$. After 2 weeks of cultivation, cells were collected for PCR, which was performed in duplicate for each sample,

\section{Gene expression}

Total RNA was extracted from the electrospun meshes, or from the films, using RNeasy Mini Kit (Qiagen) according to the manufacturer's instruction. The RNA was quantified using Nanodrop ND1000 Spectrophotometer (Witec AG, Pfäffikon, Switzerland) and $500 \mathrm{ng}$ RNA was reverse transcribed into cDNA using oligo-dT primers (Invitrogen), dNTP mix (Invitrogen), DTT (Invitrogen), 5× FSB (Invitrogen), RNA inhibitor (Applied Biosystem), and SuperscriptIII (Invitrogen). Quantitative PCR was performed in duplicates using the SYBR ${ }^{\circledR}$ Green (Qiagen) as well as primers synthesised by Microsynth (Balgach Switzerland), for primer sequences, see Table 2. Primers for CD73, CD90 and CD105 (minimal criteria (Dominici et al., 2006)), for CD31 and CD34 (markers of endothelial cells), for ALP and RUNX2 (early osteogenesis), for collagen 1 (medium osteogenesis) and osteocalcin (late osteogenesis), for PPAR- $\gamma$-2 (adipogenesis) and Sox9 (chondrogenesis) (Abdel-Sayed et al., 2014) were used. Gapdh was used as housekeeping gene. Analysis of relative gene expression of cells cultivated on a 3D electrospun mesh and on a $2 \mathrm{D}$ film was based on the $2^{\wedge}(-\Delta \Delta \mathrm{Ct})$ method (Livak and Schmittgen, 2001).

\section{Statistics}

The data were analysed with StatView 5.0.1 software. One-way statistical analysis of variance (ANOVA) was conducted to test the significance of differences between manifold inductions between 2D films and 3D electrospun meshes for the same materials and the same culture media. Pairwise comparison probabilities $(p)$ were calculated using the Fisher's PLSD post hoc test to evaluate differences between the groups. $p$ values $<0.05$ were considered significant, with $^{*}=p<0.05 ;^{* *}=p<.01$ and $^{* * *}=p<0.001$. Values are expressed as means \pm standard deviations.

\section{Results}

The focus of this study was set on investigating the gene expression variation between cells seeded on 2D or 3D scaffolds consisting of the same material. To this end we employed two different materials shown in Fig. 1a (PLGA and PLGA/aCaP) (Buschmann et al., 2012; Gao et al., 2014), in combination with two different culture media: the regular medium used for maintenance and expansion of ASCs (DMEM, $10 \%$ foetal calf serum) and osteogenic differentiation medium. In our previous work, we show that a relatively large biological variability is present between ASC lines derived from different human donors (Buschmann et al., 2013). In order to prevent bias induced through biovariability among donors, 
Table 1. (part 1) Manifold induction in gene expression, 3D electrospun mesh seeded with hASCs compared to cell-seeded 2D casted film. Key: S = Scaffold in a separate well, F = film in a separate well, S(F) = scaffold floating above film in the same well, $\mathrm{F}(\mathrm{S})=$ film beneath floating scaffold in the same well, DMEM = normal culture medium, OS = osteogenic medium.

\begin{tabular}{|c|c|c|c|c|c|c|}
\hline \multirow[b]{2}{*}{ Gene } & \multirow[b]{2}{*}{ Material } & \multirow[b]{2}{*}{ Comparison } & \multicolumn{2}{|c|}{ DMEM } & \multicolumn{2}{|c|}{ OS } \\
\hline & & & Average & Std. dev. & Average & Std. dev \\
\hline CD73 & PLGA & S vs. F & 0.55 & 0.07 & 0.92 & 0.01 \\
\hline CD73 & PLGA & $\mathrm{S}$ vs. $\mathrm{F}(\mathrm{S})$ & 0.54 & 0.07 & 0.81 & 0.01 \\
\hline CD73 & PLGA & $\mathrm{S}(\mathrm{F})$ vs. $\mathrm{F}$ & 1.14 & 0.71 & 0.51 & 0.15 \\
\hline CD73 & PLGA & $\mathrm{S}(\mathrm{F})$ vs. $\mathrm{F}(\mathrm{S})$ & 1.17 & 0.86 & 0.44 & 0.12 \\
\hline CD73 & PlGA/aCaP & S vs. F & 0.75 & 0.00 & 0.77 & 0.03 \\
\hline CD73 & PlGA/aCaP & S vs. $F(S)$ & 0.93 & 0.01 & 0.90 & 0.04 \\
\hline CD73 & PlGA/aCaP & $\mathrm{S}(\mathrm{F})$ vs. F & 1.31 & 0.35 & 0.86 & 0.23 \\
\hline CD73 & PlGA/aCaP & $\mathrm{S}(\mathrm{F})$ vs. $\mathrm{F}(\mathrm{S})$ & 1.05 & 0.22 & 1.00 & 0.18 \\
\hline CD105 & PLGA & S vs. F & 36.85 & 11.08 & 95.78 & 1.10 \\
\hline CD105 & PLGA & S vs. $\mathrm{F}(\mathrm{S})$ & 30.45 & 9.16 & 66.80 & 0.76 \\
\hline CD105 & PLGA & $\mathrm{S}(\mathrm{F})$ vs. F & 0.62 & 0.07 & 0.91 & 0.52 \\
\hline CD105 & PLGA & $\mathrm{S}(\mathrm{F})$ vs. $\mathrm{F}(\mathrm{S})$ & 0.46 & 0.08 & 0.60 & 0.22 \\
\hline CD105 & PlGA/aCaP & S vs. F & 24.93 & 8.51 & 95.78 & 1.10 \\
\hline CD105 & PlGA/aCaP & $S$ vs. $F(S)$ & 32.41 & 11.06 & 66.80 & 0.76 \\
\hline CD105 & PlGA/aCaP & $\mathrm{S}(\mathrm{F})$ vs. F & 0.48 & 0.11 & 0.57 & 0.48 \\
\hline CD105 & PlGA/aCaP & $\mathrm{S}(\mathrm{F})$ vs. $\mathrm{F}(\mathrm{S})$ & 0.63 & 0.20 & 0.46 & 0.26 \\
\hline CD90 & PLGA & S vs. F & 0.68 & 0.25 & 1.61 & 0.25 \\
\hline CD90 & PLGA & S vs. F(S) & 0.50 & 0.18 & 1.14 & 0.18 \\
\hline CD90 & PLGA & $\mathrm{S}(\mathrm{F})$ vs. F & 0.87 & 0.21 & 1.54 & 0.50 \\
\hline CD90 & PLGA & $\mathrm{S}(\mathrm{F})$ vs. $\mathrm{F}(\mathrm{S})$ & 0.63 & 0.07 & 1.07 & 0.25 \\
\hline CD90 & PlGA/aCaP & S vs. F & 0.34 & 0.12 & 1.02 & 0.33 \\
\hline CD90 & PlGA/aCaP & S vs. F(S) & 0.30 & 0.11 & 0.59 & 0.19 \\
\hline CD90 & PlGA/aCaP & $\mathrm{S}(\mathrm{F})$ vs. $\mathrm{F}$ & 0.72 & 0.40 & 0.93 & 0.26 \\
\hline CD90 & PlGA/aCaP & $\mathrm{S}(\mathrm{F})$ vs. $\mathrm{F}(\mathrm{S})$ & 0.78 & 0.75 & 0.63 & 0.49 \\
\hline$O C$ & PLGA & S vs. F & 3.20 & 0.43 & 24.78 & 6.79 \\
\hline$O C$ & PLGA & S vs. F(S) & 2.16 & 0.29 & 6.32 & 1.73 \\
\hline$O C$ & PLGA & $\mathrm{S}(\mathrm{F})$ vs. $\mathrm{F}$ & 4.02 & 1.83 & 7.63 & 2.91 \\
\hline$O C$ & PLGA & $\mathrm{S}(\mathrm{F})$ vs. $\mathrm{F}(\mathrm{S})$ & 4.68 & 6.05 & 2.44 & 1.95 \\
\hline$O C$ & PlGA/aCaP & S vs. F & 1.97 & 0.47 & 5.06 & 0.08 \\
\hline$O C$ & PlGA/aCaP & S vs. F(S) & 2.82 & 0.67 & 4.72 & 0.08 \\
\hline$O C$ & PlGA/aCaP & $\mathrm{S}(\mathrm{F})$ vs. F & 2.29 & 1.51 & 1.89 & 0.47 \\
\hline$O C$ & PlGA/aCaP & $\mathrm{S}(\mathrm{F})$ vs. $\mathrm{F}(\mathrm{S})$ & 3.37 & 2.03 & 1.53 & 0.77 \\
\hline Runx2 & PLGA & S vs. F & 2.23 & 0.37 & 3.25 & 0.25 \\
\hline Runx2 & PLGA & S vs. F(S) & 2.47 & 0.41 & 3.00 & 0.24 \\
\hline Runx2 & PLGA & $\mathrm{S}(\mathrm{F})$ vs. F & 1.75 & 0.65 & 1.50 & 0.12 \\
\hline Runx2 & PLGA & $\mathrm{S}(\mathrm{F})$ vs. $\mathrm{F}(\mathrm{S})$ & 1.90 & 0.48 & 1.39 & 0.23 \\
\hline Runx2 & PlGA/aCaP & S vs. F & 2.19 & 0.00 & 4.81 & 0.65 \\
\hline Runx2 & PlGA/aCaP & S vs. $\mathrm{F}(\mathrm{S})$ & 2.16 & 0.00 & 4.85 & 0.66 \\
\hline Runx2 & PlGA/aCaP & $\mathrm{S}(\mathrm{F})$ vs. F & 1.42 & 0.38 & 0.95 & 0.30 \\
\hline Runx2 & PlGA/aCaP & $\mathrm{S}(\mathrm{F})$ vs. $\mathrm{F}(\mathrm{S})$ & 1.41 & 0.43 & 0.98 & 0.37 \\
\hline Collagen I & PLGA & S vs. F & 0.67 & 0.15 & 0.87 & 0.14 \\
\hline Collagen I & PLGA & S vs. F(S) & 0.66 & 0.15 & 0.58 & 0.09 \\
\hline Collagen I & PLGA & $\mathrm{S}(\mathrm{F})$ vs. $\mathrm{F}$ & 1.04 & 0.13 & 2.02 & 1.10 \\
\hline Collagen I & PLGA & $\mathrm{S}(\mathrm{F})$ vs. $\mathrm{F}(\mathrm{S})$ & 1.06 & 0.39 & 1.27 & 0.37 \\
\hline Collagen I & PlGA/aCaP & S vs. F & 0.56 & 0.10 & 0.57 & 0.03 \\
\hline Collagen I & PlGA/aCaP & S vs. F(S) & 0.32 & 0.06 & 0.59 & 0.03 \\
\hline Collagen I & PlGA/aCaP & $\mathrm{S}(\mathrm{F})$ vs. $\mathrm{F}$ & 0.62 & 0.24 & 0.61 & 0.22 \\
\hline Collagen I & PlGA/aCaP & $\mathrm{S}(\mathrm{F})$ vs. $\mathrm{F}(\mathrm{S})$ & 0.36 & 0.16 & 0.62 & 0.15 \\
\hline
\end{tabular}


Table 1. (part 2) Manifold induction in gene expression, 3D electrospun mesh seeded with hASCs compared to cell-seeded 2D casted film. Key: $\mathrm{S}=$ Scaffold in a separate well, F = film in a separate well, $\mathrm{S}(\mathrm{F})=$ scaffold floating above film in the same well, $\mathrm{F}(\mathrm{S})=$ film beneath floating scaffold in the same well, DMEM = normal culture medium, $\mathrm{OS}=$ osteogenic medium.

\begin{tabular}{|c|c|c|c|c|c|c|}
\hline \multirow[b]{2}{*}{ Gene } & \multirow[b]{2}{*}{ Material } & \multirow[b]{2}{*}{ Comparison } & \multicolumn{2}{|c|}{ DMEM } & \multicolumn{2}{|c|}{ OS } \\
\hline & & & Average & Std. dev. & Average & Std. dev. \\
\hline ALP & PLGA & S vs. F & 0.18 & 0.05 & 0.11 & 0.02 \\
\hline ALP & PLGA & S vs. F(S) & 0.15 & 0.04 & 0.19 & 0.03 \\
\hline ALP & PLGA & $\mathrm{S}(\mathrm{F})$ vs. F & 1.89 & 0.87 & 0.73 & 0.17 \\
\hline ALP & PLGA & $\mathrm{S}(\mathrm{F})$ vs. $\mathrm{F}(\mathrm{S})$ & 1.58 & 0.61 & 1.30 & 0.46 \\
\hline ALP & PlGA/aCaP & S vs. F & 0.09 & 0.01 & 0.07 & 0.03 \\
\hline ALP & PlGA/aCaP & S vs. F(S) & 0.15 & 0.01 & 0.12 & 0.05 \\
\hline ALP & PlGA/aCaP & $\mathrm{S}(\mathrm{F})$ vs. F & 0.49 & 0.06 & 0.30 & 0.07 \\
\hline ALP & PlGA/aCaP & $\mathrm{S}(\mathrm{F})$ vs. $\mathrm{F}(\mathrm{S})$ & 0.90 & 0.39 & 0.58 & 0.42 \\
\hline CD31 & PLGA & S vs. F & 0.86 & 0.28 & 0.50 & 0.11 \\
\hline CD31 & PLGA & S vs. F(S) & 0.68 & 0.23 & 0.61 & 0.13 \\
\hline CD31 & PLGA & $S(F)$ vs. F & 5.50 & 4.38 & 1.34 & 0.27 \\
\hline CD31 & PLGA & $\mathrm{S}(\mathrm{F})$ vs. $\mathrm{F}(\mathrm{S})$ & 4.25 & 3.06 & 1.96 & 1.56 \\
\hline CD31 & PlGA/aCaP & S vs. F & 2.20 & 0.29 & 0.35 & 0.08 \\
\hline CD31 & PlGA/aCaP & $\mathrm{S}$ vs. $\mathrm{F}(\mathrm{S})$ & 1.16 & 0.15 & 0.83 & 0.18 \\
\hline CD31 & PlGA/aCaP & $S(F)$ vs. F & 8.95 & 1.97 & 1.35 & 0.96 \\
\hline CD31 & PlGA/aCaP & $\mathrm{S}(\mathrm{F})$ vs. $\mathrm{F}(\mathrm{S})$ & 4.62 & 0.19 & 2.88 & 1.33 \\
\hline CD34 & PLGA & S vs. F & 0.72 & 0.28 & 1.58 & 0.08 \\
\hline CD34 & PLGA & S vs. F(S) & 0.34 & 0.13 & 4.66 & 0.24 \\
\hline CD34 & PLGA & $\mathrm{S}(\mathrm{F})$ vs. F & 5.24 & 3.27 & 0.35 & 0.09 \\
\hline CD34 & PLGA & $\mathrm{S}(\mathrm{F})$ vs. $\mathrm{F}(\mathrm{S})$ & 2.35 & 1.04 & 1.37 & 1.31 \\
\hline CD34 & PlGA/aCaP & S vs. F & 0.14 & 0.06 & 0.32 & 0.12 \\
\hline CD34 & PlGA/aCaP & S vs. F(S) & 0.10 & 0.04 & 1.08 & 0.40 \\
\hline CD34 & PlGA/aCaP & $\mathrm{S}(\mathrm{F})$ vs. $\mathrm{F}$ & 2.30 & 1.22 & 0.42 & 0.28 \\
\hline CD34 & PlGA/aCaP & $\mathrm{S}(\mathrm{F})$ vs. $\mathrm{F}(\mathrm{S})$ & 1.50 & 0.42 & 1.26 & 0.31 \\
\hline PPAR- $\gamma-2$ & PLGA & S vs. F & 7.42 & 2.75 & 13.87 & 1.04 \\
\hline PPAR $-\gamma-2$ & PLGA & S vs. F(S) & 8.88 & 3.29 & 24.65 & 1.85 \\
\hline PPAR $-\gamma-2$ & PLGA & $\mathrm{S}(\mathrm{F})$ vs. F & 1.94 & 1.55 & 0.37 & 0.18 \\
\hline PPAR- $\gamma-2$ & PLGA & $\mathrm{S}(\mathrm{F})$ vs. $\mathrm{F}(\mathrm{S})$ & 2.54 & 2.80 & 0.62 & 0.18 \\
\hline PPAR $-\gamma-2$ & PlGA/aCaP & S vs. F & 4.83 & 0.19 & 5.95 & 0.33 \\
\hline PPAR- $\gamma-2$ & PlGA/aCaP & S vs. F(S) & 8.20 & 0.32 & 7.89 & 0.44 \\
\hline PPAR- $\gamma-2$ & PlGA/aCaP & $\mathrm{S}(\mathrm{F})$ vs. F & 0.57 & 0.13 & 0.11 & 0.10 \\
\hline PPAR $-\gamma-2$ & PlGA/aCaP & $\mathrm{S}(\mathrm{F})$ vs. $\mathrm{F}(\mathrm{S})$ & 0.98 & 0.37 & 0.11 & 0.07 \\
\hline Sox9 & PLGA & S vs. F & 0.26 & 0.04 & 0.50 & 0.13 \\
\hline Sox9 & PLGA & S vs. F(S) & 0.21 & 0.03 & 0.38 & 0.10 \\
\hline Sox9 & PLGA & $\mathrm{S}(\mathrm{F})$ vs. $\mathrm{F}$ & 1.14 & 0.57 & 4.17 & 3.36 \\
\hline Sox9 & PLGA & $S(\mathrm{~F})$ vs. $\mathrm{F}(\mathrm{S})$ & 0.94 & 0.31 & 2.34 & 0.55 \\
\hline Sox9 & PlGA/aCaP & S vs. F & 0.19 & 0.00 & 0.13 & 0.03 \\
\hline Sox9 & PlGA/aCaP & S vs. F(S) & 0.15 & 0.00 & 0.14 & 0.03 \\
\hline Sox9 & PlGA/aCaP & $\mathrm{S}(\mathrm{F})$ vs. F & 1.43 & 0.22 & 0.58 & 0.07 \\
\hline Sox9 & PlGA/aCaP & $\mathrm{S}(\mathrm{F})$ vs. $\mathrm{F}(\mathrm{S})$ & 1.22 & 0.18 & 1.18 & 0.33 \\
\hline
\end{tabular}


Table 2. The sequences of forward and reverse primers.

\begin{tabular}{|c|c|c|}
\hline Gene & & Sequence $\left(5^{\prime}-3^{\prime}\right)$ \\
\hline \multirow[t]{2}{*}{ GAPDH } & forward & ACC ACA GTC CAT GCC ATC AC \\
\hline & reverse & TCC ACC ACC CTG TTG CTG TA \\
\hline \multirow[t]{2}{*}{ CD31 } & forward & ATT GCA GTG GTT ATC ATC GGA GTG \\
\hline & reverse & CTC GTT GTT GG AGT TCA GAA GTG G \\
\hline \multirow[t]{2}{*}{ CD34 } & forward & TGA AGC CTA GCC TGT CAC CT \\
\hline & reverse & CGC ACA GCT GGA GGT CTT AT \\
\hline \multirow[t]{2}{*}{ CD73 } & forward & СТС СТС TCA ATC ATG CCG CT \\
\hline & reverse & CCC AGG TAA TTG TGC CAT TGT \\
\hline \multirow[t]{2}{*}{ CD90 } & forward & TGA ATA CAG ACT GCA CCT CCC \\
\hline & reverse & CTT GAC GGG TGA GGC TAG GA \\
\hline \multirow[t]{2}{*}{ CD105 } & forward & CAG CAG TGT CTT CCT GCA TC \\
\hline & reverse & AGT TCC ACC TTC ACC GTC AC \\
\hline \multirow[t]{2}{*}{ ALP } & forward & CTG GTA GTT GTT GTG AGC AT \\
\hline & reverse & CCC AAA GGC TTC TTC TTG \\
\hline \multirow[t]{2}{*}{ Osteocalcin } & forward & CAC TCC TCG CCC TAT TGG C \\
\hline & reverse & CCC TCC TGC TTG GAC ACA AAG \\
\hline \multirow[t]{2}{*}{ Runx2 } & forward & GAA CCC AGA AGG CAC AGA CA \\
\hline & reverse & GGC TCA GGT AGG AGG GCT \\
\hline \multirow[t]{2}{*}{ COL1 } & forward & TGA CGA GAC CAA GAA CTG \\
\hline & reverse & CCA TCC AAA CCA CTG AAA CC \\
\hline \multirow[t]{2}{*}{ PPAR- -2} & forward & AGG AGC AGA GCA AAG AGG \\
\hline & reverse & CCT CGG ATA TGA GAA CCC \\
\hline \multirow[t]{2}{*}{ Sox 9} & forward & СTC TGG AGA CTT CTG AAC GAG AGC \\
\hline & reverse & GTT CTT CAC CGA CTT CCT CCG \\
\hline
\end{tabular}

we decided to use ASCs from one single donor for this study. These cells fulfilled the minimal criteria of the International Society for Cellular Therapy for defining mesenchymal stem cells (Dominici et al., 2006): plastic adherence, differentiation capacity towards adipocytes, chondrocytes and osteoblasts in vitro (Fig. 6 and 7 ) and surface marker expression of CD73, CD90 and CD105. In order to test the feasibility of the experiments, ASCs were first seeded either on flat PLGA and PLGA/aCaP films or on a three-dimensional randomly electrospun mesh of both materials. Growth capacity of ASCs on films and meshes was assessed by H\&E staining (Fig. 1b). Cells seeded on the 3D scaffold migrated through the fibres and distributed homogenously throughout the whole scaffold. In contrast, cells seeded on the flat 2D casted films were not able to grow into the material a PLGA

Film $1000 \mathrm{~nm}$

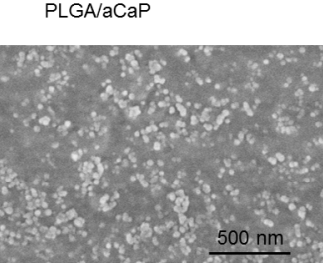

Mesh
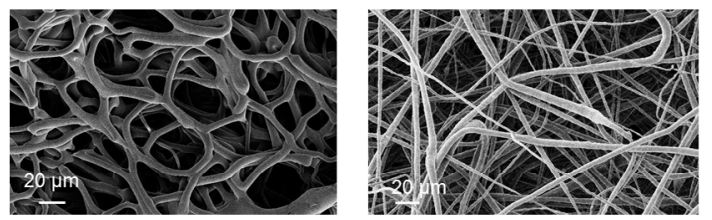

b

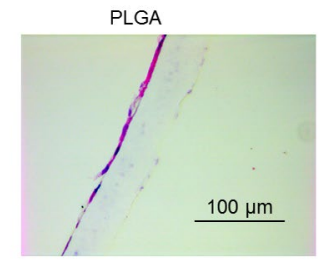

PLGA/aCaP
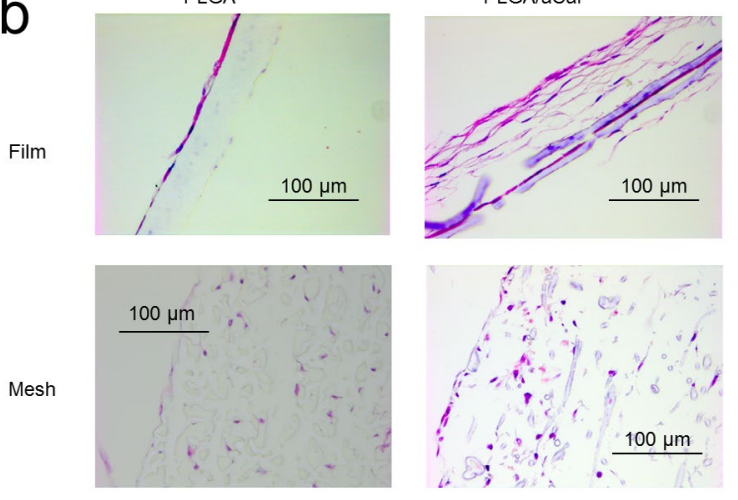

C

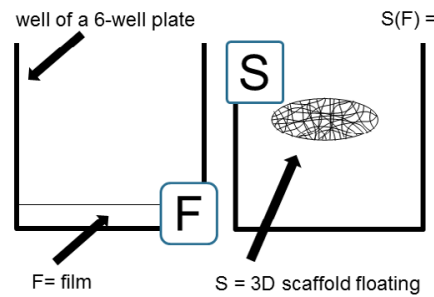

$S(F)=3 D$ scaffold floating above film

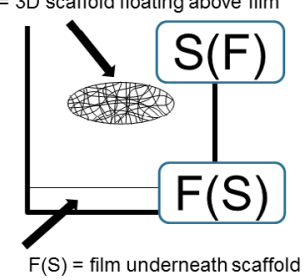

Fig. 1. Scaffolds and experimental setup. a) SEM images of films and electrospun meshes composed of PLGA and PLGA/aCaP, respectively. While the films of PLGA are completely flat on their surface, the nanoparticles in the PLGA/aCaP films are reasonably visible. $\mathbf{b})$ Histological sections of cellseeded 2D films and scaffolds, both either of PLGA or PLGA/aCaP. c) Scheme of 6-well plate with film alone, scaffold alone or in combination. The rationale behind the latter combined setup (co-system) was to assess paracrine effects between cells seeded on a film beneath a cell-seeded floating scaffold that were not in touch with each other.

but were mainly located at the surface of the film. This was explainable by the fact that a casted film was completely dense and there were no pores through which cells might migrate into the material (Fig. 1b).

In order to address paracrine effects, gene expression of cells seeded in a 3D mesh were compared not only to cells seeded on a 2D film cultivated in a separate well, but also on a film placed in the same well underneath the floating scaffold and vice versa for cell-seeded 2D films (Fig. 1c). 
CD73

CD73

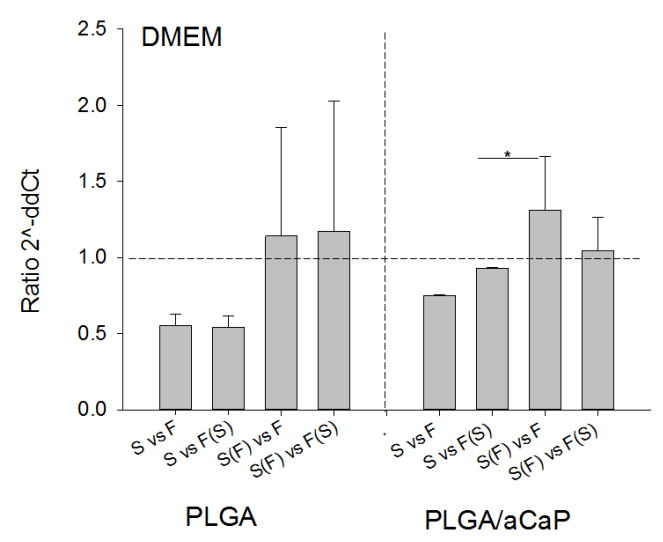

a

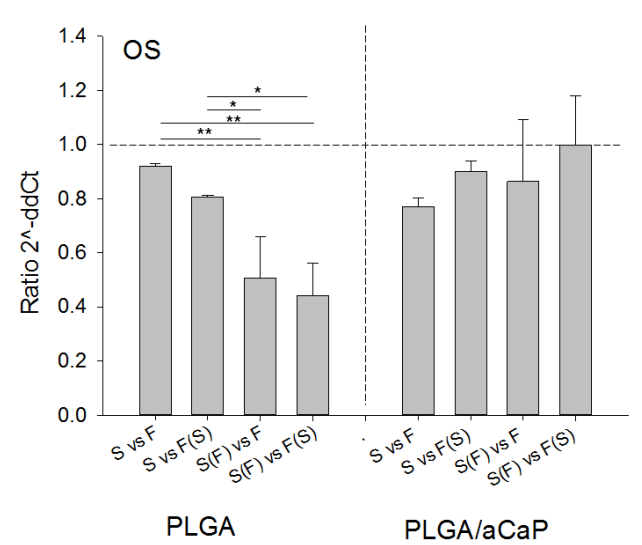

CD105

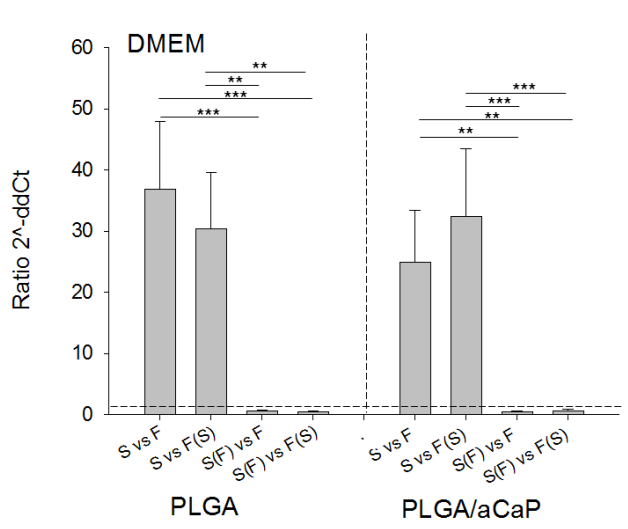

CD105

C

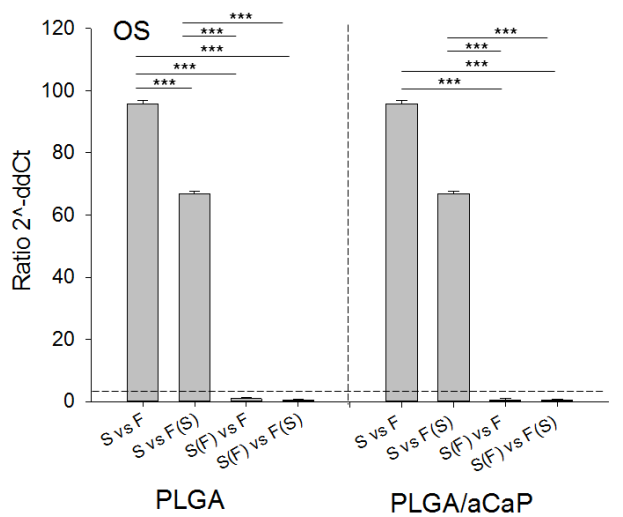

CD90

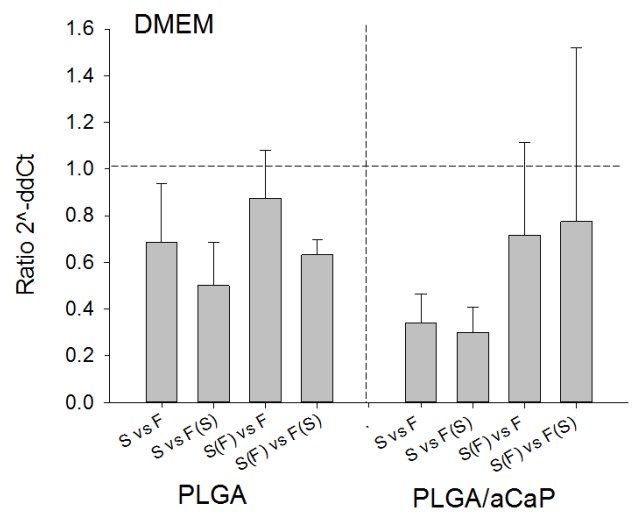

e

CD90

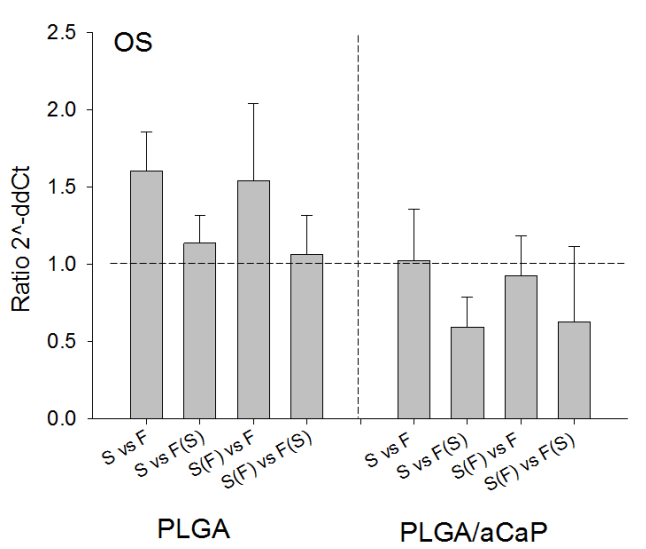

Fig. 2. PCR results with respect to minimum essential markers. a-f) Manifold gene expression (= fold change) of ASCs seeded on a 3D electrospun mesh compared to a 2D film of the same material and in the same culture medium. Typical stem cell markers, CD73, CD105 and CD90, respectively, are shown. The horizontal dashed line marks no change in gene expression. The vertical dashed line separates the two different materials denoted below (PLGA vs. PLGA/aCaP). Key: vs = versus; F(S) = film underneath floating $3 \mathrm{D}$ scaffold; $\mathrm{F}=$ film in a separate well of culture dish, $S=$ scaffold in a separate well of culture dish. DMEM = normal culture medium; OS = osteogenic medium; for statistical analysis, one-way ANOVA was conducted and * $=p<0.05$; ${ }^{* *}=p<0.01$ and $^{* * *}=p<0.001$. 
ALP

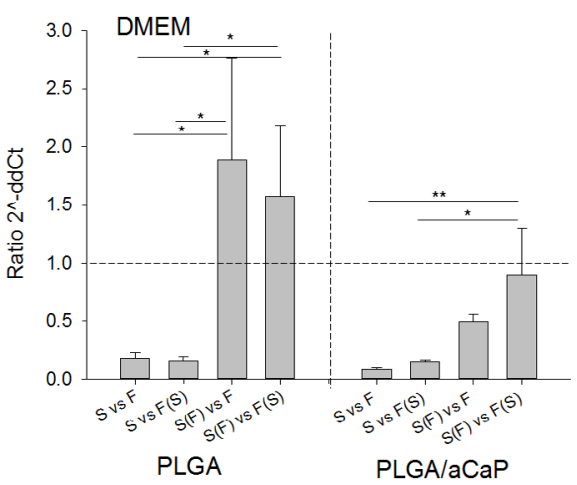

Runx2

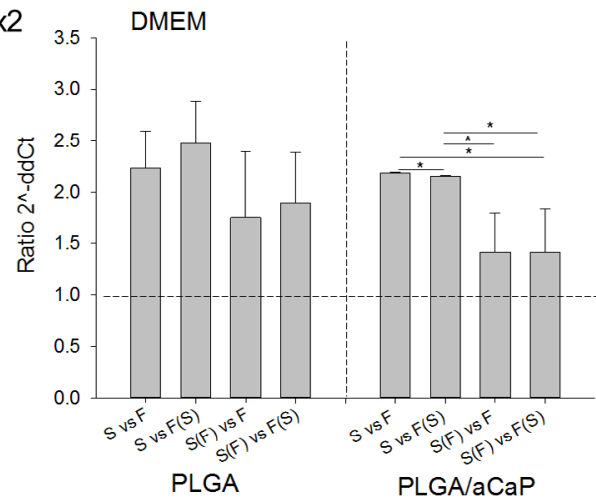

Collagen I

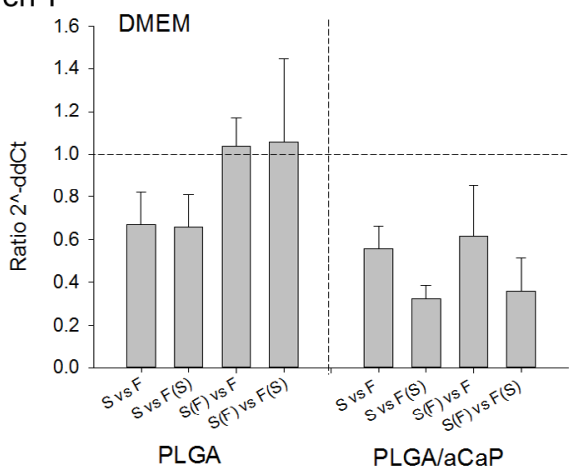

Osteocalcin

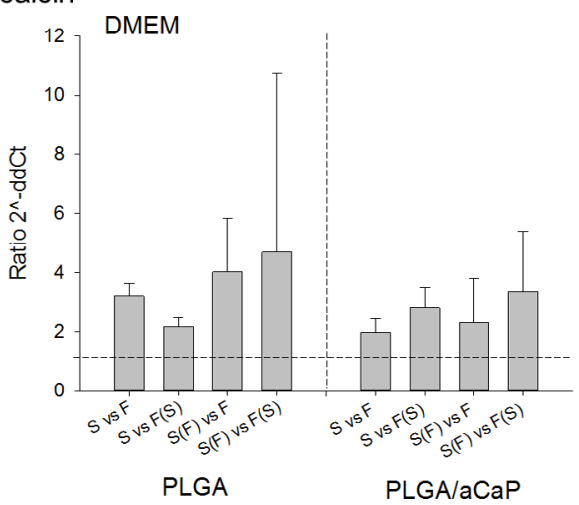

a ALP

b

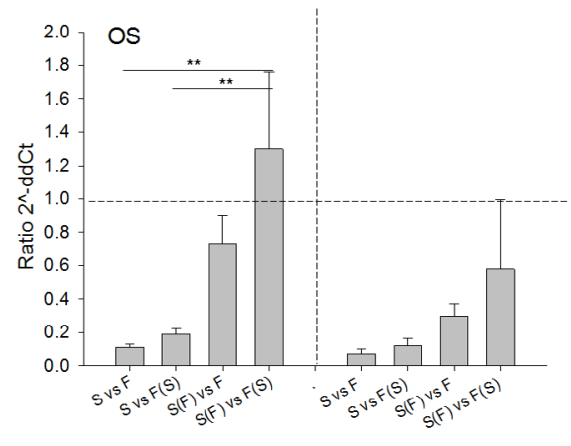

C

PLGA

PLGA/aCaP

d

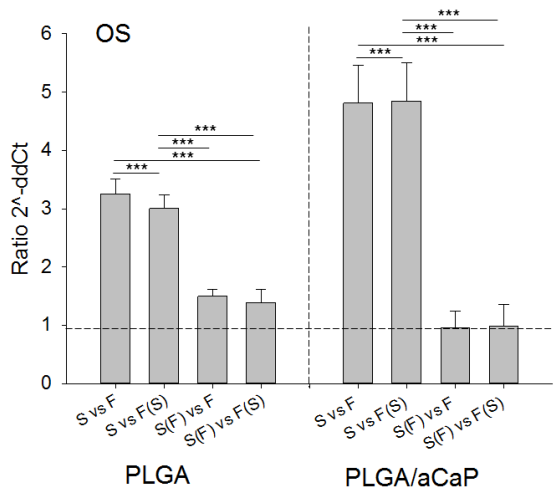

e

Collagen I

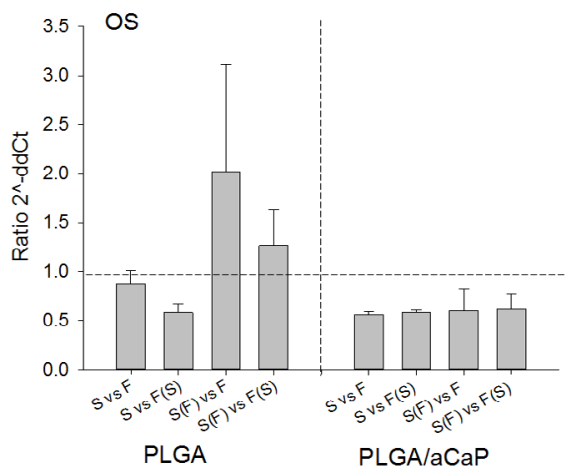

Osteocalcin

h

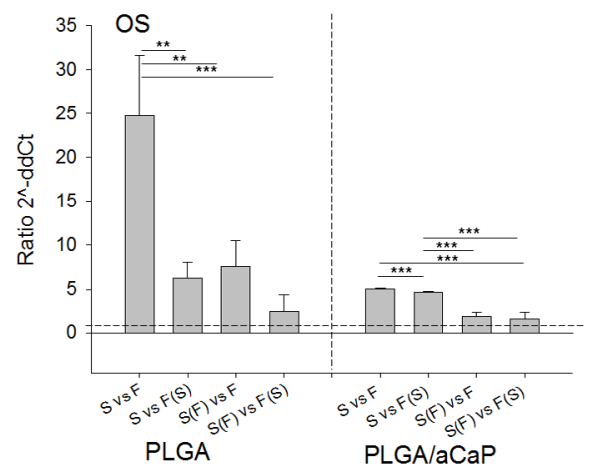

Fig. 3. PCR results with respect to osteogenesis. a-h) Typical osteogenic markers are shown; ALP, Runx2, Collagen I and Osteocalcin. The horizontal dashed line marks no change in gene expression. The vertical dashed line separates the two different materials denoted below (PLGA vs. PLGA/aCaP). Key: vs = versus; $\mathrm{F}(\mathrm{S})=$ film underneath floating $3 \mathrm{D}$ scaffold; $\mathrm{F}=$ film in a separate well of culture dish, $\mathrm{S}=$ scaffold in a separate well of culture dish., DMEM = normal culture medium; OS = osteogenic medium; for statistical analysis, one-way ANOVA was conducted and ${ }^{*}=p<0.05 ;^{* *}=p<0.01$ and ${ }^{* *}=p<0.001$. 
Gene expression differences between 3D versus $2 \mathrm{D}$ are summarised in Table 1 and illustrated in Fig. 2-5.

\section{Minimum criteria stem cell markers}

We first assessed changes in the characteristic MSC markers under the different culture conditions. CD73 as well as CD105 were differentially expressed in cells seeded on 3D scaffolds compared to those seeded on 2D films, regardless of both the material they were exposed to and the culture medium. When 3D meshes were compared to 2D films, CD73 was downregulated and CD105 was upregulated. This upregulation was only found for 3D meshes cultivated separately (Fig. 2). Interestingly, the situation in the co-system was different, where a downregulation of CD105 was measured. Expression of CD90 was reduced for the 3D meshes, compared to the films in DMEM for both materials. In OS only the PLGA/aCaP system shows reduced CD90 expression levels.

\section{Osteogenesis}

During osteogenesis, upregulated genes at early time points include ALP and Runx2 (Knippenberg et al., 2006), followed by collagen I and at later time points osteocalcin. Therefore, these typical markers for osteogenesis were analysed after 2 weeks in vitro culture. ASCs cultured on 3D scaffolds generally expressed lower ALP levels compared to the corresponding 2D films, regardless of the medium and the material (Fig. 3a,b). Interestingly, if 3D scaffolds were co-cultured with cell-seeded 2D films an inverse effect was observed; the gene expression being increased.

Runx2 was upregulated on 3D scaffolds, regardless of the material or medium the cells were exposed to. When co-culturing cells seeded on films or 3D scaffolds, Runx2 upregulation decreased, especially in the OS medium (Fig. 3c,d). Moreover, gene expression of collagen I was downregulated in cells growing on 3D scaffolds compared to 2D films. The expression level only increased in the 3D PLGA/ OS combination when the meshes were co-cultured (Fig. $3 \mathbf{e}, \mathbf{f})$. Importantly, osteocalcin was upregulated under all conditions tested in cells grown on 3D scaffolds compared to 2D films (Fig. 3g,h).

\section{Angiogenesis}

CD34 gene expression was upregulated in the co-system for both media and materials and
CD34

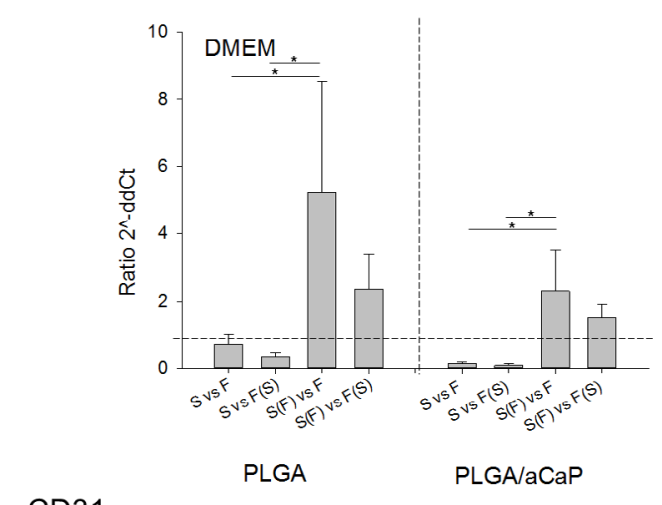

CD31

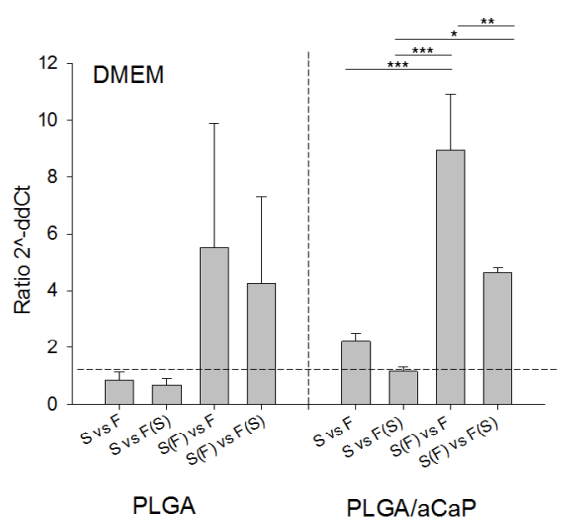

CD34

a

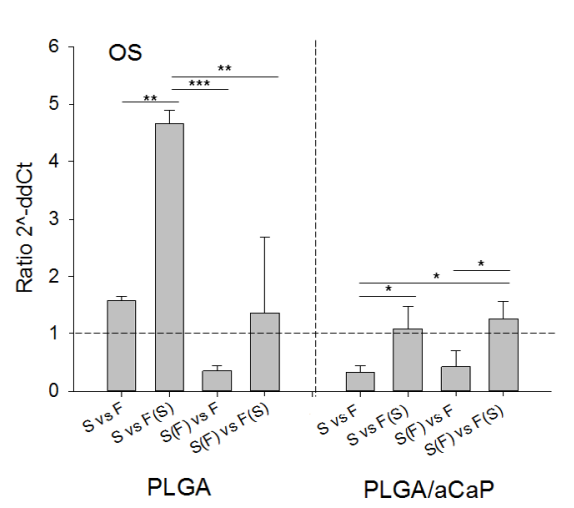

CD31

C

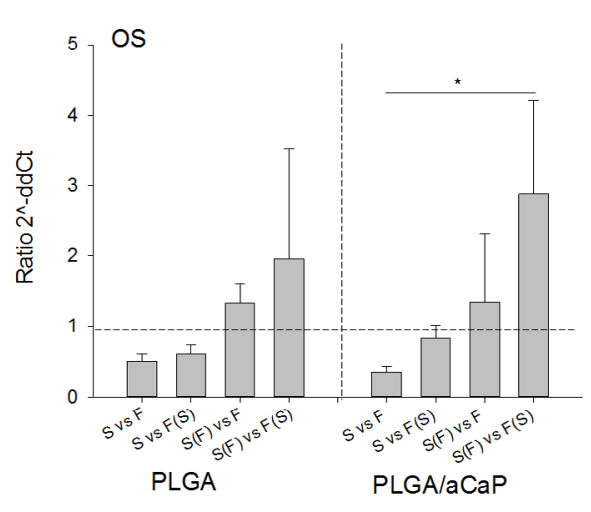

Fig. 4. PCR results with respect to endothelial cell differentiation. a-d) Manifold CD34 and CD31 expression of ASCs seeded on a 3D electrospun mesh compared to a 2D film. The horizontal dashed line marks no change in gene expression. The vertical dashed line separates the two different materials denoted below (PLGA vs. PLGA/aCaP). Key: vs = versus; $\mathrm{F}(\mathrm{S})$ = film underneath floating 3D scaffold; $\mathrm{F}=$ film in a separate well of culture dish, $\mathrm{S}=$ scaffold in a separate well of culture dish. DMEM = normal culture medium; OS = osteogenic medium; for statistical analysis, one-way ANOVA was conducted and ${ }^{*}=p<0.05 ;{ }^{* *}=p<0.01$ and ${ }^{* * *}=p<0.001$. 
PPAR- $\gamma-2$

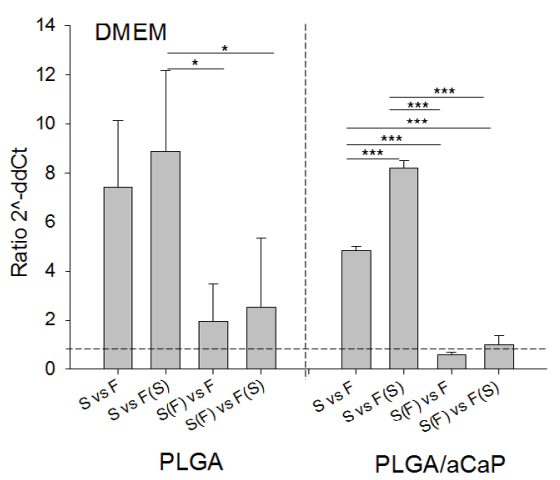

Sox9

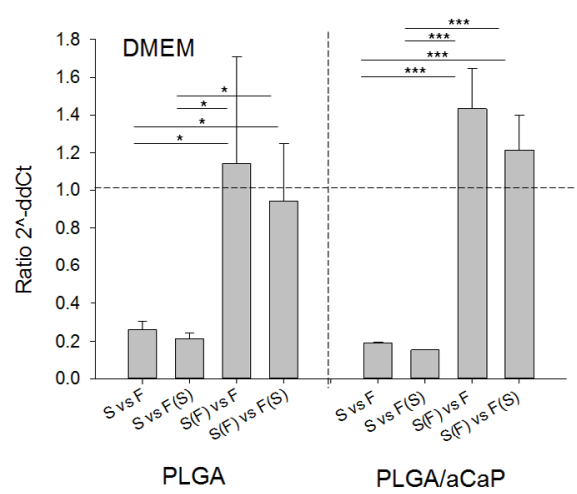

PPAR- $\gamma-2$

a

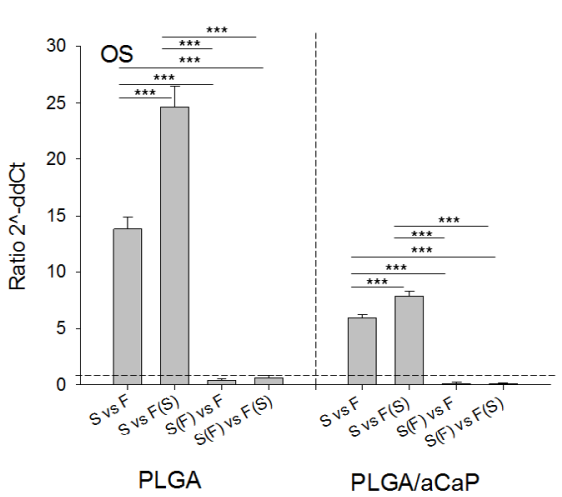

b

Sox9

C

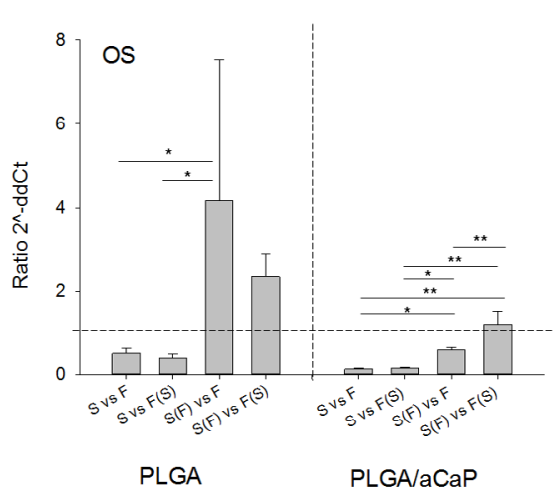

Fig. 5. PCR results with respect to adipogenesis and chondrogenesis. a-b) Manifold PPAR- $\gamma-2$ (adipogenesis) and c-d) Sox9 (chondrogenesis) expression of ASCs seeded on a 3D electrospun mesh compared to a 2D film. The horizontal dashed line marks no change in gene expression. The vertical dashed line separates the two different materials denoted below (PLGA vs. PLGA/aCaP). Key: vs = versus; $F(S)=$ film underneath floating 3D scaffold; $F=$ film in a separate well of culture dish, $S=$ scaffold in a separate well of culture dish. DMEM = normal culture medium; OS = osteogenic medium; for statistical analysis, one-way ANOVA was conducted and $^{*}=p<0.05 ;{ }^{* *}=p<0.01$ and ${ }^{* * *}=p<0.001$.

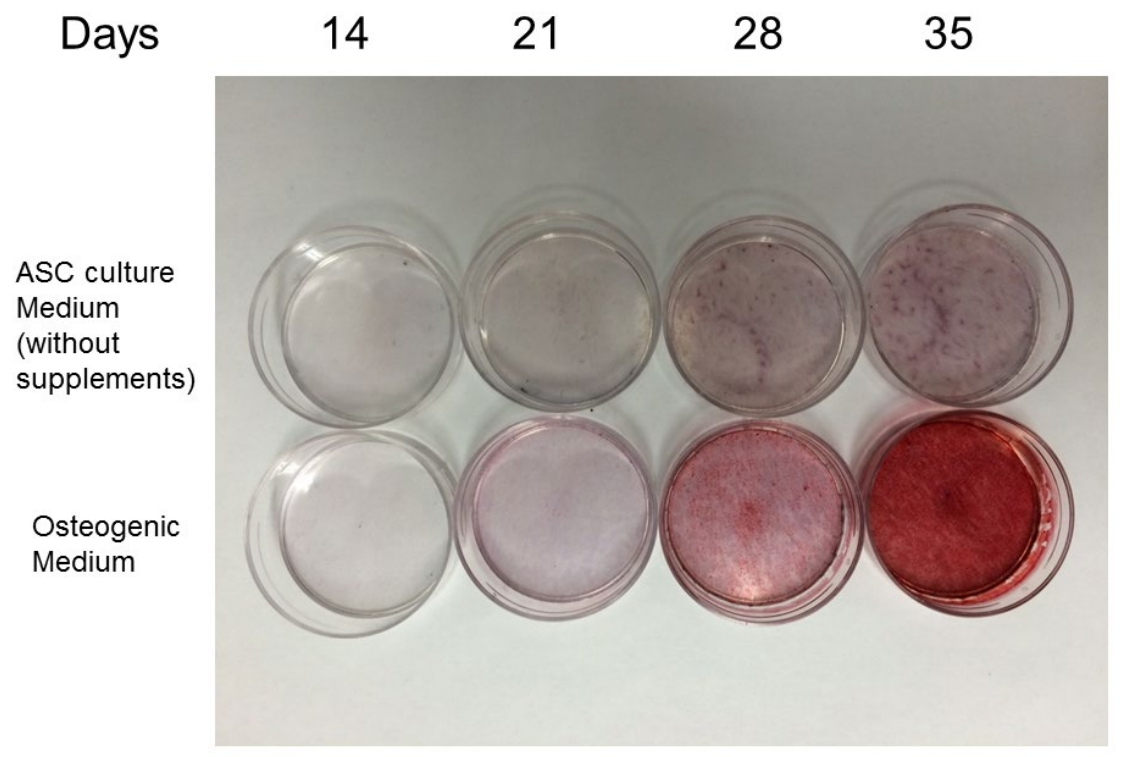

Fig. 6. Osteogenic differentiation. Compared to ASC culture medium without any supplements, ASCs in osteogenic medium started deposition of calcium ions around 3 weeks post-induction. Note: after $14 \mathrm{~d}$, no difference is yet seen between the two conditions with different culture media in the Alizarin Red staining although commitment has been triggered, which was assessed by RT-PCR. 


\section{Adipogenic Differentiation (Oil red)}
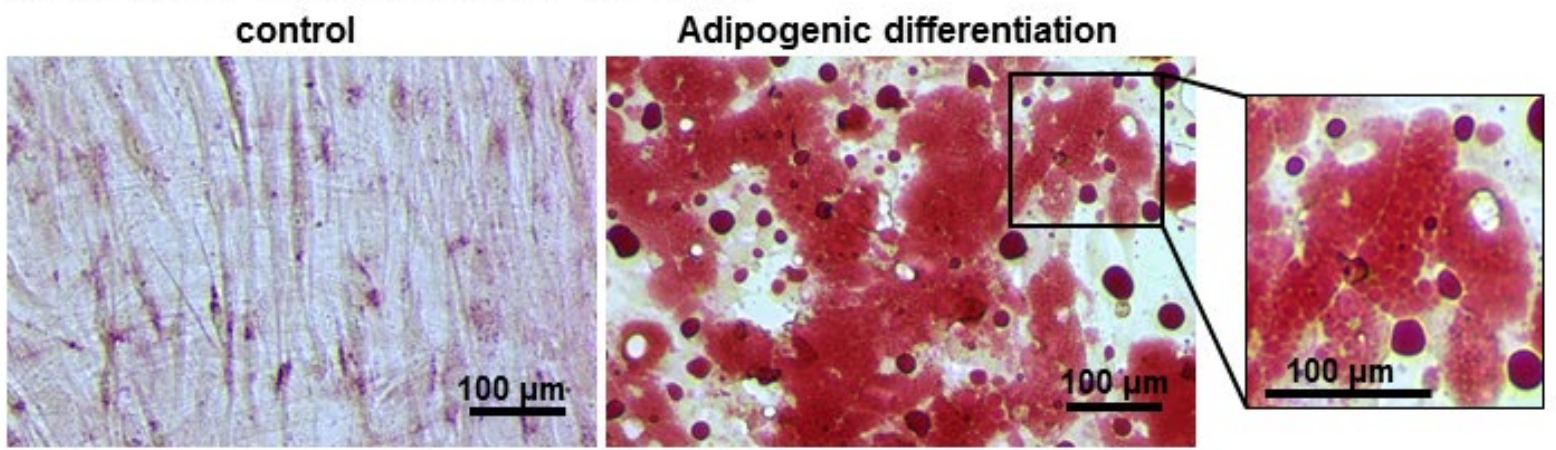

\section{Osteogenic Differentiation (von Kossa)}
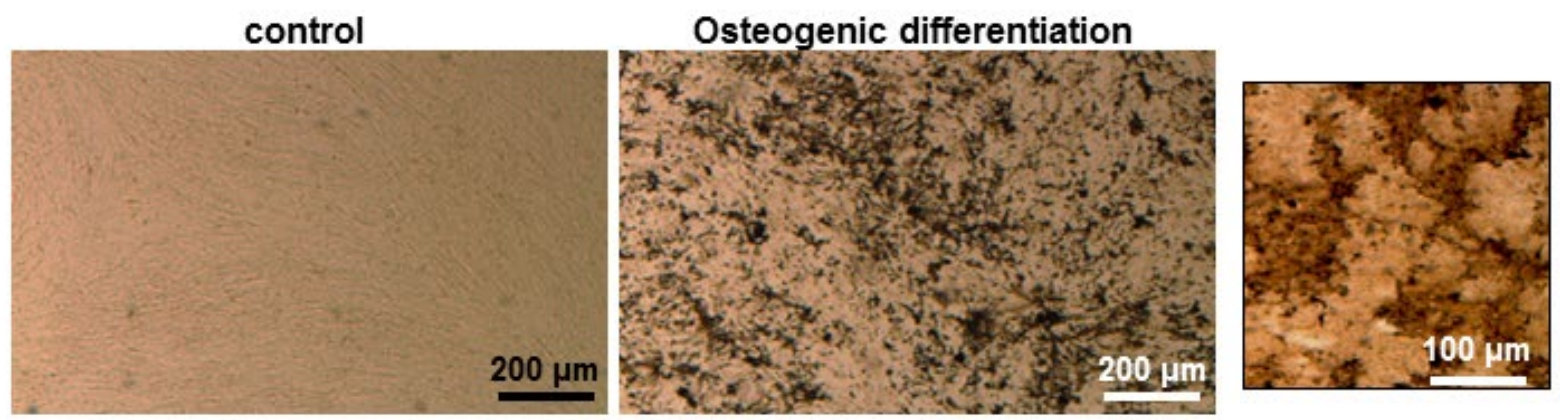

\section{Chondrogenic Differentiation (Alician blue)}

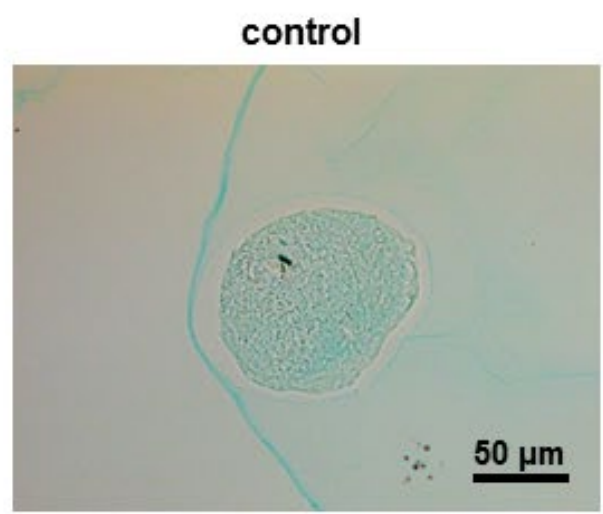

\section{Chondrogenic differentiation}

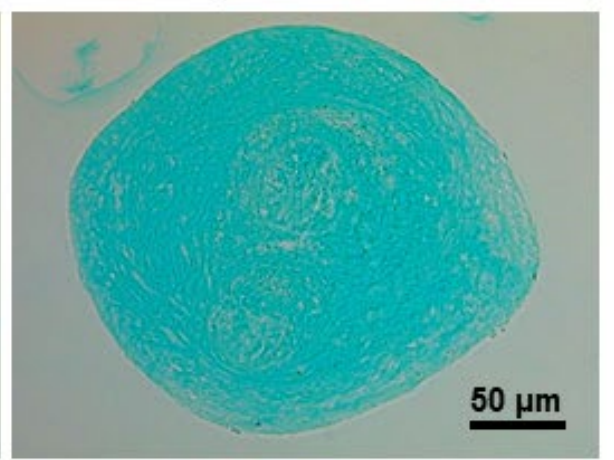

\section{Endothelial Differentiation (CD31 IHC)}
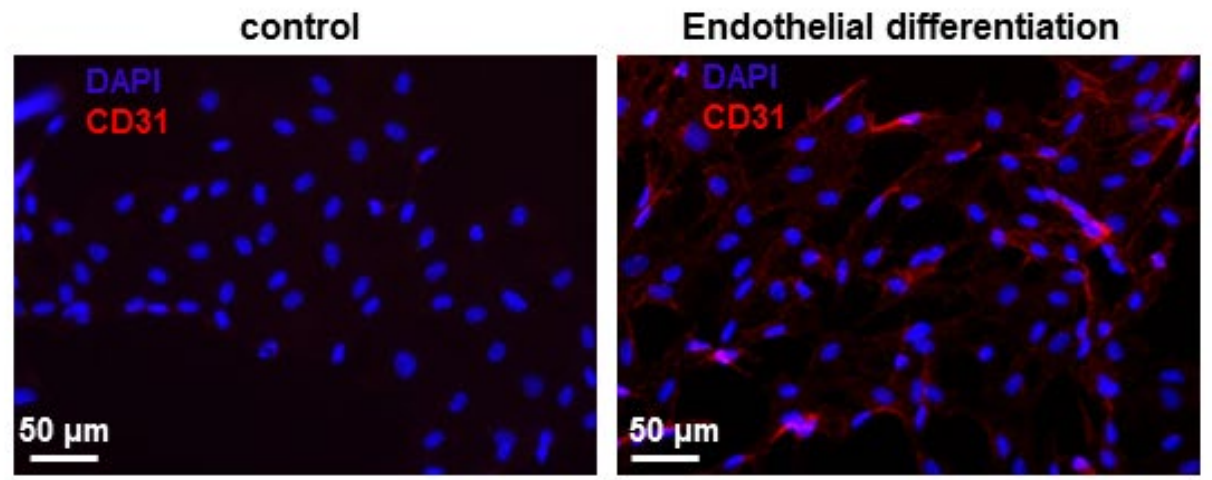

Fig. 7. Differentiation of ASCs. Oil Red O staining to verify adipogenic differentiation of undifferentiated cells and of cells undergoing adipogenic differentiation for 4 weeks; van Kossa staining of undifferentiated and osteogenic differentiated cells at 3 weeks of differentiation; Alcian Blue staining of undifferentiated cells and cells undergoing chondrogenesis for 5 weeks; CD31 staining of undifferentiated cells and of cells differentiated towards the endothelial cell line at time point 3 weeks. 


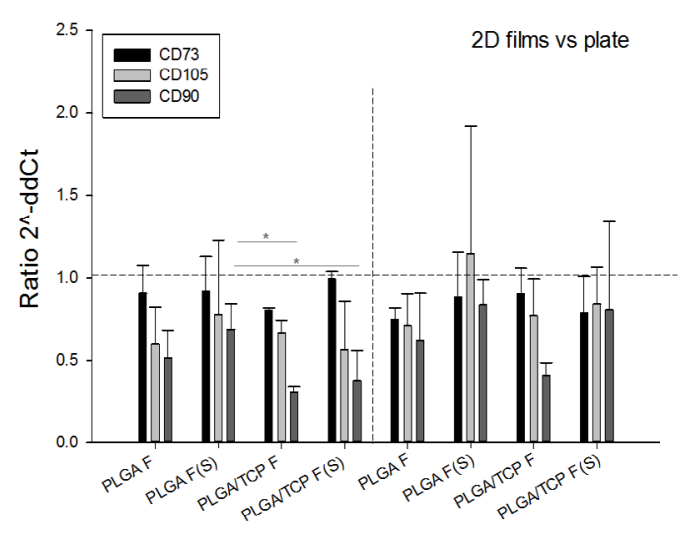

a

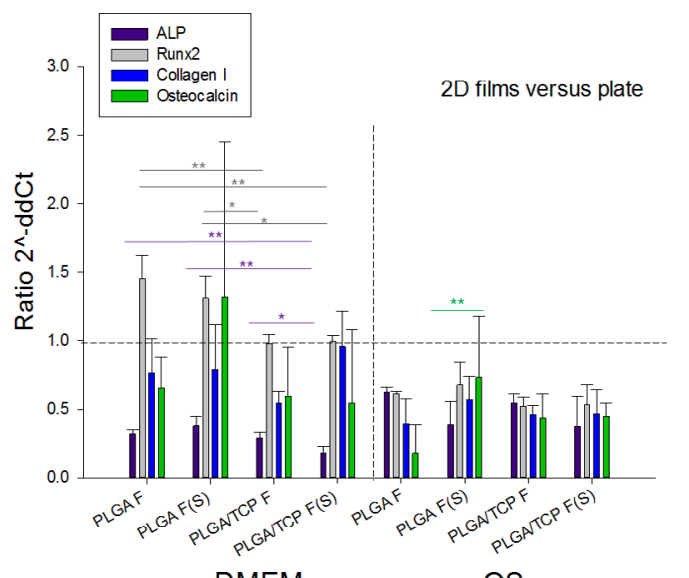

b
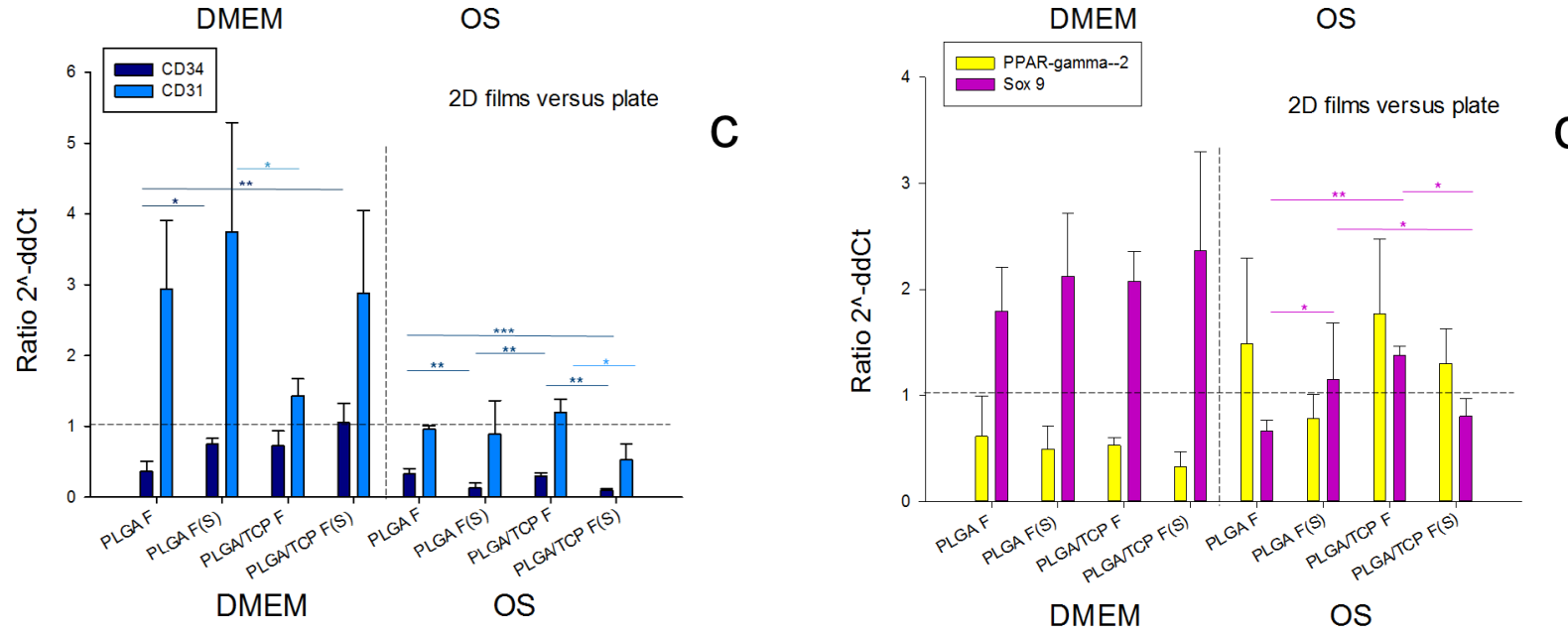

Fig. 8. PCR results for 11 genes; comparison of 2D films to polystyrene culture plate. ASCs seeded on 2D films compared to culture plate: manifold expression of according genes. Minimum criteria stem cell markers (upper left), typical osteogenic markers (upper right), angiogenesis markers (below left) and adipogenesis and chondrogenesis markers, respectively (below right). Key: $\mathrm{F}=$ casted film in a separate well of culture dish, not underneath 3D scaffold; $F(S)=$ casted film underneath floating 3D scaffold, but not in contact with the 3D scaffold (= co-system). For statistical analysis, one-way ANOVA was conducted and ${ }^{*}=p<0.05$; ${ }^{* *}=p<0.01$ and ${ }^{* * *}=p<0.001$.

downregulated for the separately cultivated systems, except for pure PLGA meshes in OS (Fig. 4a,b). CD31 gene expression of ACSs seeded on 3D scaffolds was decreased for both materials in OS and slightly decreased for PLGA meshes in DMEM compared to their corresponding 2D films (Fig. 4c,d). However, when 3D meshes were co-cultivated with seeded films, CD31 was clearly upregulated.

\section{Adipogenesis}

One of the most important genes in adipogenesis is peroxisome proliferator-activated receptor (PPAR)- $\gamma$-2 (Schipper et al., 2008). The effect of changing the environment from $2 \mathrm{D}$ films to $3 \mathrm{D}$ meshes on the PPAR- $\gamma$ - 2 expression depended on the culture media and the material (Fig. 5a,b). The combination of PLGA/DMEM upregulated PPAR- $\gamma-2$ expression. In OS, an upregulation for PPAR $-\gamma-2$ was also found, but only if systems were separated (no paracrine function). In the co-system, a downregulation of this gene was found, especially low for PLGA/aCaP.

\section{Chondrogenesis}

Sox9 expression, a typical marker of chondrogenesis, was analysed (Fig. 5c,d). Regardless of the material and medium used for ASC cultivation, a clear downregulation of Sox9 was detected for the 3D mesh - when compared to the 2D film. In contrast, the co-cultured 3D environment increased the expression of Sox9, with the only exception of the PLGA/aCaP in OS - there, a downregulation was found.

\section{Plate-2D film comparison}

In addition to the comparison in gene expression of ASCs seeded in 2D and 3D environments, gene expression of ASCs seeded on a 2D film was also compared to that of ASCs seeded on a polystyrene culture plate with the corresponding culture media (Fig. 8). The material had a significant impact on gene expression levels, especially for osteogenic, endothelial, chondrogenic and adipogenic cell markers - and, to a lesser extent, for typical stemness markers., For example, cell-seeded PLGA films cultivated in OS led to a downregulation of Sox9, 


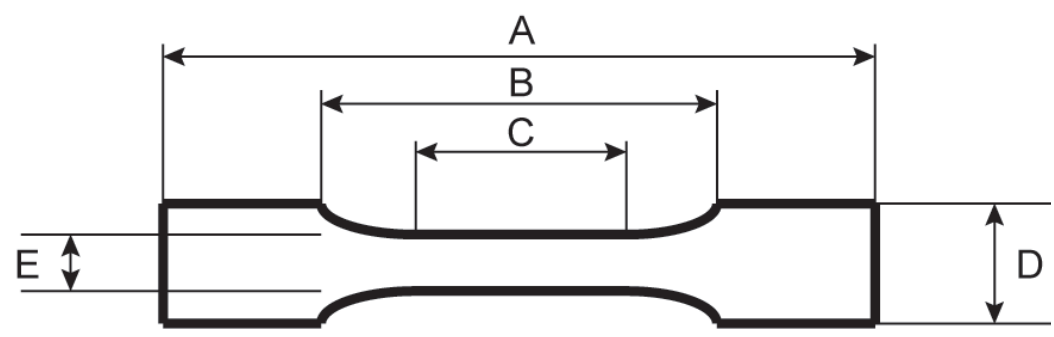

Fig. 9. Standard dimensions for cutting dumbbell specimen. The values of the dimensions are $A=50 \mathrm{~mm}, B=27.5 \mathrm{~mm}, \mathrm{C}=15 \mathrm{~mm}$, $\mathrm{D}=8.5 \mathrm{~mm}$ and $\mathrm{E}=4 \mathrm{~mm}$.
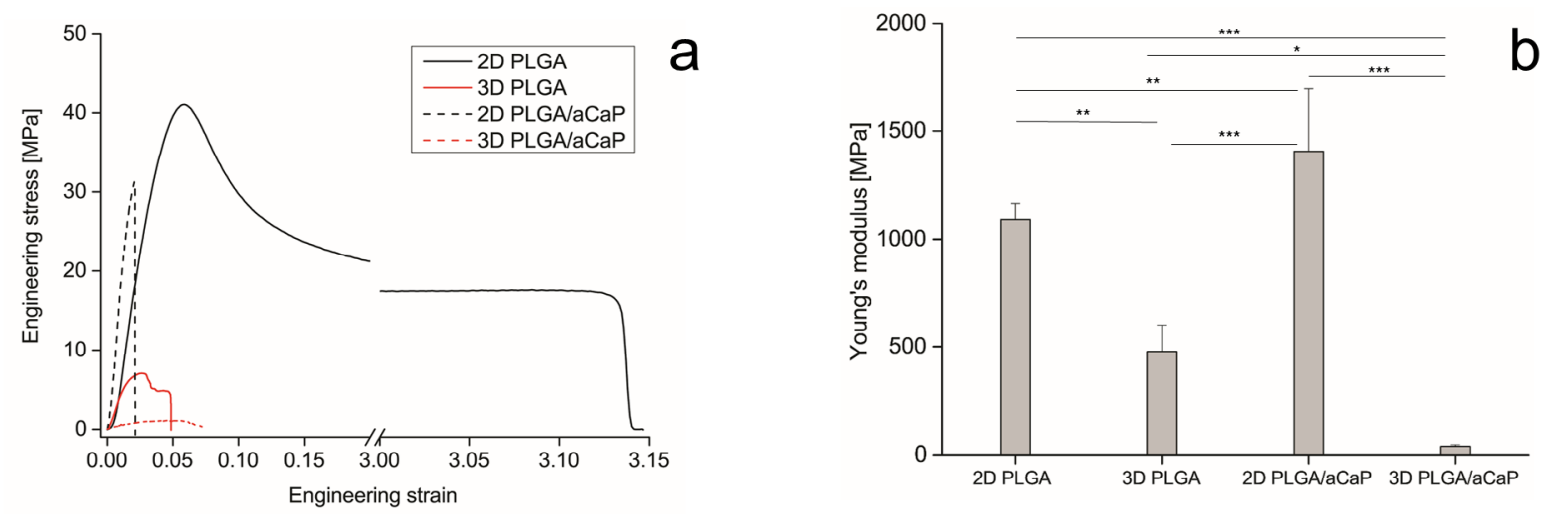

Fig. 10. Bulk mechanical properties of 2D films and meshes, composed either of PLGA or PLGA/aCaP. a) Engineering stress-strain curves, b) Young's moduli. For statistical analysis, one-way ANOVA was conducted and ${ }^{*}=p<0.05 ; * *=0.01$ and ${ }^{* * *}=p<0.001$.

while cell-seeded PLGA/aCaP films in OS showed the opposite - an upregulation of Sox9 (Fig. 8d).

\section{Paracrine effects, cell cross-talk}

In order to assess paracrine effects, cell-seeded 3D meshes and 2D films were not only cultivated in separate, but also in the same well. The 3D mesh was floating above the 2D film, which was located at the bottom of the well (Fig. 1c). If a paracrine function was active, the $S(F)$ vs. $F(S)$ induction (in the co-system) should have been closer to a ratio of 1 as compared to the $S$ vs. F induction ( $S$ and $F$ each in a separate well, respectively). This would have been because of secreted factors influencing gene expression of cells, seeded either on the 3D mesh or the 2D films. Out of the 44 different possible combinations (11 genes, with 2 materials and 2 culture media), 28 systems revealed this effect. Hence, in over $60 \%$ of all conditions, a levelling paracrine effect was found, indicating the extreme importance of not only the direct microenvironment, but also of the cellular cross-talk via cytokines and other secreted factors.

\section{Mechanical properties of materials}

Besides fold changes in gene expression and assessing paracrine effects, the bulk mechanical properties of the $2 \mathrm{D}$ films and $3 \mathrm{D}$ meshes were determined.
Engineering stress-strain curves, of PLGA and PLGA/aCaP films and meshes, were recorded and Young's modulus was calculated based on these measurements (Fig. 10). While 2D films exhibited higher moduli when compared to 3D meshes, for both materials, the absolute and relative differences were different for the two materials; the modulus of 2D PLGA was $1091 \pm 74 \mathrm{MPa}$ and the 3D PLGA mesh had $491 \pm 95 \mathrm{MPa}$. For the PLGA/aCaP, the corresponding values were $1405 \pm 292 \mathrm{MPa}$ and 3850 $\pm 9 \mathrm{MPa}$, respectively.

\section{Discussion}

Adult stem cells represent an interesting cell source for a huge variety of tissue engineering and regenerative medicine approaches (Mueller and Loring, 2014; Wu and Belmonte, 2015). Cell morphology, physiology but also the capacity and efficiency of differentiation toward a specific cell type strongly depend on the environment. In organisms, cells build 3D structures. Cultivating and differentiating cells in a 3D environment is therefore physiological. Morphology, gene expression, and overall biological response of cells assessed in 3D culture models are often more similar to natural 
tissues. Furthermore, cellular organisation in 3D meshes allows the establishment of cell-to-cell and cell-to-matrix interactions, regulating cellular functions. Therefore, it is not surprising that a number of studies comparing $3 \mathrm{D}$ to $2 \mathrm{D}$ culture conditions have been published. As expected, these studies show promising effects in terms of the 3D microenvironment affecting the intended stem cell differentiation (Ma et al., 2014). Nevertheless, a typical characteristic of these studies is that the comparison is often performed on different materials. Frequently, cells are cultivated in 2D on polystyrene cell culture dishes - a very different material from that provided in the 3D systems (Castren et al., 2015).

This comparison method might bias the results of the experiments, because the extracellular matrix, cell morphology and cell-to-cell interactions are no longer similar. Therefore, the main focus of our study was the "real" 2D-3D comparison, by using the same material for both 2D and 3D conditions. The study was conducted using plain PLGA and PLGA/aCaP composite 2D films and electrospun 3D scaffolds. Additionally, the gene expression was measured of cells seeded on common polystyrene Petri dishes and their expression compared to that one of cells seeded on 2D PLGA films (Fig. 8). Our results illustrated the strong influence of the different materials on the gene expression and demonstrated the importance of using appropriate controls when comparing 2D and 3D systems.

Interestingly, only two genes, Runx2 and osteocalcin, out of 11 investigated genes showed similar trends under all conditions, which included the co-culturing of two scaffolds in one well, when comparing the $3 \mathrm{D}$ to the $2 \mathrm{D}$ scenario. More specifically, we observed an overall upregulation in Runx2 and osteocalcin for cells seeded on 3D scaffolds (Fig. 3c,d). Both genes belong to the group of typical osteogenic markers. Other genes from this group are ALP and collagen I, which experienced a slight downregulation for 3D versus $2 \mathrm{D}$ (Fig. $\mathbf{3 a}, \mathbf{b}, \mathbf{e}, \mathbf{f})$. These findings may be explained by the analysis time point. PCR analysis was performed $14 \mathrm{~d}$ after cell seeding. At this time point differentiating cells normally express more ALP during osteogenesis (Dang et al., 2016). This upregulation period may already have been passed in the potentially osteogenic PLGA/aCaP material and especially in OS. Although the osteo-inductive characteristics of aCaP nanoparticles suspended in DMEM are known (Buschmann et al., 2012), the effect of the same nanoparticles incorporated in PLGA, as realised in PLGA/aCaP, still needed demonstrating. As for paracrine signalling, there was a clear and compelling "levelling effect" in ALP and Runx2 for all conditions and for osteocalcin in OS (Fig. $3 \mathbf{a}, \mathbf{b}, \mathbf{c}, \mathbf{d}, \mathbf{g}, \mathbf{h})$. The "levelling effect" indicated that cells on 2D films in the co-system secreted factors that influenced gene expression of cells on 3D meshes in the co-system - and vice versa. Thereby, the ratio of gene expression was levelled towards an equal expression level (value 1). We concluded from these findings that osteogenesis of ASCs was more strongly promoted in a 3D fibre mesh compared to a 2D film.

As for the stemness markers, we found a downregulation for CD73 and CD90 to various extents, indicating that the cells started differentiation in the 3D mesh and progressively lost the expression of these stemness markers (Fig. 2a, b b,e,f). ASCs, especially when compared to bone marrow-derived or dermal skin derived stem cells, exhibit less stability in terms of stemness under the influence of differentiation inducing agents (Ock et al., 2013). Against our expectations, CD105 did not exhibit similar expression patterns to CD73 and CD90. Significant upregulation of this factor was detected in ASCs, cultured on both materials and media in separate wells. In contrast, for the cocultured probes, a strong paracrine effect was noted leading to decreased CD105 expression levels. The relationship between CD105 and osteogenesis is known. Higher levels of CD105 in human ASCs favours osteogenic differentiation, compared to adipogenic differentiation, when compared to the non-sorted corresponding ASCs (Jiang et al., 2010). Moreover, CD105 positive bone-marrow derived stromal cells exhibit an osteogenic commitment (Aslan et al., 2006). On the other hand, a depletion in protein CD105 enhances osteogenesis (Levi et al., 2011), making the role of CD105 during osteogenic differentiation rather controversial. Nevertheless, the upregulation of CD105 from 2D to 3D in separate systems was in agreement with an upregulation of osteocalcin under all conditions and might, therefore, concur with the findings for CD105 enriched human ASCs with an osteogenic commitment (Jiang et al., 2010).

Promotion of angiogenesis and neovascularisation is an inherent requirement in tissue engineered constructs, because of the need for sufficient oxygen and nutrient supplies (Laschke and Menger, 2015). Therefore, differentiation of stem cells towards the endothelial cell type is a crucial step towards a functional cell-seeded scaffold (Gao et al., 2014). Increase of CD31 and CD34 expression levels indicated endothelial cell differentiation. CD31 was downregulated in nearly all single cultured scaffolds, regardless the material or the medium (Fig. 4c,d). However, when the 3D scaffolds were co-cultured with a second scaffold, strong CD31 upregulation was detected. CD34 seemed to be influenced more strongly by the medium, as single cultured 3D PLGA scaffolds exhibited upregulated expression levels when cultured in OS. This showed that a 3D environment, such as a fibrous mesh, supports the differentiation of at least a subset of ASCs towards the endothelial cell phenotype when co-cultured with a seeded 2D film. This emphasises the importance of the paracrine function by cells seeded on a 3D mesh or a 2D film (Wang et al., 2015) secreting soluble factors during their early differentiation. These factors influenced the cells seeded on the films underneath (and vice versa) and thereby initiated a response. 
Interestingly, while a levelling effect was detected for CD34, no levelling effect could be observed for CD31 (Fig. 4a,b,c,d).

For in vitro as well as in vivo adipogenesis, peroxisome proliferator-activated receptor PPAR- $\gamma-2$ activation is essential (Halvorsen et al., 2000). Our study revealed that the PPAR $-\gamma-2$ expression in ASCs was differentially affected on both 2D and 3D structures (Fig. 5a,b). While cells cultured in the cosystem and seeded on 3D PLGA scaffolds in DMEM experienced an increased expression, this effect was opposite to that in OS. The downregulation in OS was even stronger when PLGA/aCaP rather than PLGA scaffolds were co-cultured in the same well. The presence of aCaP nanoparticles and the OS, including $10^{-7} \mathrm{M}$ dexamethasone, had an antiadipogenic influence on cells seeded on 3D scaffolds only. Dexamethasone induces adipogenesis at higher concentrations (between $10^{-6}$ and $2.5 \times 10^{-}$ $\left.{ }^{6} \mathrm{M}\right)$ (Sun et al., 2003) and regulates the balance between adipogenesis and osteogenesis (Liu et al., 2009). If the ERK pathway is blocked, for example, the presence of dexamethasone triggers a switch from osteo- to adipogenesis (Liu et al., 2009). Here, ASCs experienced a significant downregulation of this adipogenic-essential gene on PLGA/aCaP/OS in the co-system. This is a further indication that $\mathrm{aCaP}$ nanoparticles induce the osteogenic rather than the adipogenic differentiation in human adipose-derived stem cells. In the separate systems, 3D vs. 2D showed an upregulation of PPAR- $\gamma-2$, while the co-system showed a clear levelling effect. Again, paracrine signals have important effects and significantly influence the balance between adipoand osteogenesis. As osteogenic genes, like Runx2 and osteocalcin, were upregulated in nearly all systems and PPAR- $\gamma-2$ only in the single-cultured scaffolds, it might be worthwhile using 3D meshenvironments in the presence of cells seeded onto analogous 2D films. This might be a way to direct ASCs more exclusively towards osteoblasts and suppress their adipogenic differentiation.

The chondrogenic marker Sox9 expression was decreased in cells cultured in either medium or material, when single 3D scaffolds were cultured. However, despite the OS medium in the co-system, the $3 \mathrm{D}$ environment and material might have been more important in terms of differentiation commitment than the supplementation in driving the osteogenic differentiation. Short time changes to the 3D environment (only for minutes) affect the differentiation of MSCs. Changing the spacer arm length of an RGD ligand coupled to a hydrogel, influences the differentiation of mouse derived bone marrow stromal cells towards either osteogenesis or chondrogenesis (Lee et al., 2016).

Although the focus was on peeling-out the effect of the mere transition from $2 \mathrm{D}$ to $3 \mathrm{D}$, the change in substrate stiffness that is inherent to dimensional changes also needed consideration. There were decreases in substrate moduli for both materials,
PLGA as well as PLGA/aCaP, from a $2 \mathrm{D}$ film to a 3D fibre mesh. However, as the absolute and relative differences varied for the two materials, the different changes in gene expression might also be attributed to this change to some extent. Moreover, these bulk material properties were assessed under dry conditions, which were only restrictively predictive of the stiffness the cells encountered in their wet microenvironment. Nevertheless, when the transition from 2D to 3D was studied for the same material, in different culture media, variations in changes concerning gene expressions still occurred, which again emphasised that (apart from mechanical properties) an adequate and corresponding 2D control material should be chosen when the advantages of a 3D fibre network are claimed.

\section{Conclusions}

Initially, strong alterations in gene expression for cells seeded on either polystyrene or PLGA and PLGA/ aCaP 2D films were confirmed. This was the first study focusing on the variation to cell-differentiation relevant gene expression in 3D and $2 \mathrm{D}$ cultures of human ACSs seeded on the same materials. Importantly, increased osteocalcin expression levels indicated that the 3D environment promoted osteogenesis in ASCs, regardless the material or medium used. Furthermore, analysis of the CD73 and CD90 gene expression led to the conclusion that ASCs lost part of their stemness when the cells were exposed to a 3D network of fibres, compared to the 2D surface. Interestingly, if cell-seeded 3D and 2D structures were cultured in the same well, there was two-way paracrine interaction that was significant in most cases and predominated by a levelling effect. Finally, our data highlighted the importance of using appropriate controls (e.g. same materials) when comparing 2D and 3D culture conditions. These findings provided a new perspective on experimental culturing set-ups and might inspire further studies in the field of tissue engineering.

\section{Acknowledgements}

We thank Miss Pia Fuchs for her help with histology.

\section{Disclosure}

The authors confirm that there are no conflicts of interest.

\section{References}

Abdel-Sayed P, Darwiche SE, Kettenberger U, Pioletti DP (2014) The role of energy dissipation of polymeric scaffolds in the mechanobiological 
modulation of chondrogenic expression. Biomaterials 35: 1890-1897.

Aslan H, Zilberman Y, Kandel L, Liebergall M, Oskouian RJ, Gazit D, Gazit Z (2006) Osteogenic differentiation of noncultured immunoisolated bone marrow-derived CD105(+) cells. Stem Cells 24: 17281737.

Buschmann J, Gao S, Härter L, Hemmi S, Welti M, Werner CML, Calcagni M, Cinelli P, Wanner GA (2013) Yield and proliferation rate of adipose-derived stem cells as a function of age, BMI and harvest site: Increasing the yield by using adherent and supernatant fractions? Cytotherapy 15: 1098-1105.

Buschmann J, Härter L, Gao S, Hemmi S, Welti M, Hild N, Schneider OD, Stark WJ, Lindenblatt N, Werner CML, Wanner GA, Calcagni M (2012) Tissue engineered bone grafts based on biomimetic nanocomposite PLGA/amorphous calcium phosphate scaffold and human adipose-derived stem cells. Injury 43: 1689-1697.

Castren E, Sillat T, Oja S, Noro A, Laitinen A, Konttinen YT, Lehenkari P, Hukkanen M, Korhonen M (2015) Osteogenic differentiation of mesenchymal stromal cells in two-dimensional and three-dimensional cultures without animal serum. Stem Cell Res Ther 6: 167-177.

Dang PN, Dwivedi N, Yu X, Phillips L, Bowerman C, Murphy WL, Alsberg E (2016) Guiding chondrogenesis and osteogenesis with mineralcoated hydroxyapatite and BMP-2 incorporated within high-density hMSC aggregates for bone regeneration. ACS Biomat Sci Eng 2: 30-42.

Diederich VEG, Studer P, Kern A, Lattuada M, Storti G, Sharma RI, Snedeker JG, Morbidelli M (2013) Bioactive polyacrylamide hydrogels with gradients in mechanical stiffness. Biotechnol Bioeng 110: 15081519.

Dominici M, Le Blanc K, Mueller I, SlaperCortenbach I, Marini FC, Krause DS, Deans RJ, Keating A, Prockop DJ, Horwitz EM (2006) Minimal criteria for defining multipotent mesenchymal stromal cells. The International Society for Cellular Therapy position statement. Cytotherapy 8: 315-317.

Emmert MY, Wolint P, Wickboldt N, Gemayel G, Weber B, Brokopp CE, Boni A, Falk V, Bosman A, Jaconi ME, Hoerstrup SP (2013) Human stem cellbased three-dimensional microtissues for advanced cardiac cell therapies. Biomaterials 34: 6339-6354.

Gao SP, Calcagni M, Welti M, Hemmi S, Hild N, Stark WJ, Meier Buergisser G, Wanner GA, Cinelli P, Buschmann J (2014) Proliferation of ASC-derived endothelial cells in a 3D electrospun mesh: Impact of bone-biomimetic nanocomposite and co-culture with ASC-derived osteoblasts. Injury 45: 974-980.

Gronthos S, Franklin DM, Leddy HA, Robey PG, Storms RW, Gimble JM (2001) Surface protein characterization of human adipose tissue-derived stromal cells. J Cell Physiol 189: 54-63.

Halvorsen YC, Wilkison WO, Gimble JM (2000) Adipose-derived stromal cells - their utility and potential in bone formation. Int J Obes 24: S41-S44.
Heo J, Nam H, Hwang D, Cho SJ, Jung S-Y, Cho D-W, Shim J-H, Lim G (2016) Enhanced cellular distribution and infiltration in a wet electrospun three-dimensional fibrous scaffold using eccentric rotation-based hydrodynamic conditions. Sensors and Actuators B-Chemical 226: 357-363.

Jiang T, Liu W, In XJ, Sun HY, Zhang L, Liu Y, Zhang WJ, Cao YL, Zhou GD (2010) Potent in vitro chondrogenesis of CD105 enriched human adiposederived stem cells. Biomaterials 31: 3564-3571.

Kapur SK, Wang X, Shang H, Yun S, Li X, Feng G, Khurgel M, Katz AJ (2012) Human adipose stem cells maintain proliferative, synthetic and multipotential properties when suspension cultured as selfassembling spheroids. Biofabrication 4: 025004.

Knippenberg M, Helder MN, Doulabi BZ, Wuisman P, Klein-Nulend J (2006) Osteogenesis versus chondrogenesis by BMP-2 and BMP-7 in adipose stem cells. Biochem Biophys Res Commun 342: 902-908.

Laschke MW, Menger MD (2015) Adipose tissue-derived microvascular fragments: natural vascularization units for regenerative medicine. Trends Biotechnol 33: 442-448.

Lee JW, Kim H, Lee KY (2016) Effect of spacer arm length between adhesion ligand and alginate hydrogel on stem cell differentiation. Carbohydrate Polymers 139: 82-89.

Levi B, Wan DC, Glotzbach JP, Hyun J, Januszyk M, Montoro D, Sorkin M, James AW, Nelson ER, LiS, Quarto N, Lee M, Gurtner GC, Longaker MT (2011) CD105 protein depletion enhances human adiposederived stromal cell osteogenesis through reduction of transforming growth factor $\beta 1$ (TGF- $\beta 1$ ) signaling. J Biol Chem 286: 39497-39509.

Li Y, Kilian KA (2015) Bridging the gap: from 2D cell culture to 3D microengineered extracellular matrices. Adv Healthc Mater 4: 2780-2796.

Lima J, Goncalves AI, Rodrigues MT, Reis RL, Gomes ME (2015) The effect of magnetic stimulation on the osteogenic and chondrogenic differentiation of human stem cells derived from the adipose tissue (hASCs). J Magnetism Magn Mat 393: 526-536.

Lin Q, Wang L, Bai Y, Hu M, Mo J, He H, Lou A, Yang B, Zhao H, Guo Y, Wu Y, Wang L (2016) Effect of the co-culture of human bone marrow mesenchymal stromal cells with human umbilical vein endothelial cells in vitro. J Recept Signal Transduct Res 36: 221224.

Liu Q, Cen L, Zhou H, Yin S, Liu G, Liu W, Cao Y, Cui L (2009) The role of the extracellular signalrelated kinase signaling pathway in osteogenic differentiation of human adipose-derived stem cells and in adipogenic transition initiated by dexamethasone. Tissue Eng Part A 15: 3487-3497.

Livak KJ, Schmittgen TD (2001) Analysis of relative gene expression data using real-time quantitative PCR and the 2(T)(-Delta Delta C) method. Methods 25: 402-408.

Loher S, Stark WJ, Maciejewski M, Baiker A, Pratsinis SE, Reichardt D, Maspero F, Krumeich 
F, Gunther D (2005) Fluoro-apatite and calcium phosphate nanoparticles by flame synthesis. Chem Mater 17: 36-42.

Ma J, Yang F, Both SK, Prins H-J, Helder MN, Pan J, Cui F-Z, Jansen JA, van den Beucken JJJP (2014) In vitro and in vivo angiogenic capacity of BMMSCs/HUVECs and AT-MSCs/HUVECs cocultures. Biofabrication 6: 015005.

Mueller F-J, Loring JF (2014) A compass for stemcell differentiation. Nature 513: 498-499.

Neofytou EA, Chang E, Patloia B, Joubert LM, Rajadas J, Gambhir SS, Cheng Z, Robbins RC, Beygui RE (2011) Adipose tissue-derived stem cells display a proangiogenic phenotype on 3D scaffolds. J Biomed Mat Res Part A 98A: 383-393.

Ock S-A, Maeng G-H, Lee Y-M, Kim T-H, Kumar BM, Lee S-L, Rho G-J (2013) Donor-matched functional and molecular characterization of canine mesenchymal stem cells derived from different origins. Cell Transplant 22: 2311-2321.

Schipper BM, Marra KG, Zhang W, Donnenberg AD, Rubin JP (2008) Regional anatomic and age effects on cell function of human adipose-derived stem cells. Ann Plast Surg 60: 538-544.

Schneider OD, Loher S, Brunner TJ, Uebersax L, Simonet M, Grass RN, Merkle HP, Stark WJ (2008) Cotton wool-like nanocomposite biomaterials prepared by electrospinning: In vitro bioactivity and osteogenic differentiation of human mesenchymal stem cells. J Biomed Mat Res Part B 84B: 350-362.

Sthanam LK, Barai A, Rastogi A, Mistari VK, Maria A, Kauthale R, Gatne M, Sen S (2017) Biophysical regulation of mouse embryonic stem cell fate and genomic integrity by feeder derived matrices. Biomaterials 119: 9-22.
Sun L, Nicholson AC, Hajjar DP, Gotto AM, Hau JH (2003) Adipogenic differentiating agents regulate expression of fatty acid binding protein and CD36 in the J744 macrophage cell line. J Lipid Res 44: 18771886.

Viswanathan P, Ondeck MG, Chirasatitsin S, Ngamkham K, Reilly GC, Engler AJ, Battaglia G (2015) 3D surface topology guides stem cell adhesion and differentiation. Biomaterials 52: 140-147.

Wang K, Yu L-Y, Jiang L-Y, Wang H-B, Wang C-Y, Luo $Y$ (2015) The paracrine effects of adipose-derived stem cells on neovascularization and biocompatibility of a macroencapsulation device. Acta Biomater 15: 65-76.

Wu J, Belmonte JCI (2015) Dynamic pluripotent stem cell states and their applications. Cell Stem Cell 17: 509-525.

Xu ZC, Zhang Q, Li H (2015) Elastic large muscular vessel wall engineered with bone marrow-derived cells under pulsatile stimulation in a bioreactor. Mol Med Report 12: 6005-6012.

Zuk PA, Zhu M, Mizuno H, Huang J, Futrell JW, Katz AJ, Benhaim P, Lorenz HP, Hedrick MH (2001) Multilineage cells from human adipose tissue: Implications for cell-based therapies. Tissue Eng 7: 211-228.

Editor's notes: All questions raised by reviewers were incorporated into the revised text of the paper, so there is no Discussion with Reviewers section. The Scientific Editor for this paper was Chris Evans. 